\title{
Restructuring the South African electricity supply industry
}

Grové Steyn 


\section{Executive summary}

\section{Infroduction}

South Africa is undergoing fundamental political and constitutional change that will, for the first time, bring it democracy. After years of apartheid neglect, a democratic government will be faced with a massive demand for the delivery of public services. The provision of household electricity connection will feature high on the list of national priorities.

The national social infrastructure, including the electricity supply industry (ESI), has developed under decades of apartheid rule to serve the interest of the white minority. Most South Africans do not have access to domestic electricity and, in its current form, the ESI will not be able to fulfil the need for rapid electrification. This paper analyses the problems with the present ESI and develops a proposal for the restructuring of the industry to enable it to implement a national electrification programme.

\section{The South African electricity supply industry}

The first commercial supply of electricity is closely associated with the development of the mining industry in Kimberley when street lights were switched on in this growing mining town in 1882. Thereafter municipalities took the lead in supplying electricity to the larger cities. The discovery of gold on the Witwatersrand in 1886, and the subsequent development of the mining industry, required the generation of electricity on a more extensive scale by the early 1900 s. This need was fulfilled by private initiatives. The Victoria Falls Power Company was registered in October 1906 and others followed shortly.

After 1906 the development of the ESI can be split into four distinct periods (Horwitz 1993). (1) From 1906 to 1922 the industry consisted of a mixture of private and municipal enterprises. (2) After 1922 a national public body, the Electricity Supply Commission (Escom), cooperated with the private and municipal suppliers. Escom's aim was to facilitate the coordinated development of the power sector to ensure a cheap and abundant supply of electricity. (3) After 1948 Escom took over the Victoria Falls and Transvaal Power Company, thereby essentially monopolising the generation and transmission of electricity. (4) In 1985 Escom underwent a major restructuring after a period of poor performance. Its name was changed in 1987 to Eskom. Eskom currently supplies $98 \%$ of all the electricity generated in South Africa. It also owns and operates the national integrated transmission network that transmits high-voltage bulk electricity to all the large consumers including its own and municipal distributors.

South Africa has a total net generating capacity of about $37000 \mathrm{MW}$ and produced $149427 \mathrm{GWh}$ of electricity in 1992 (Eskom 1993a). Mining and industry consume just under $70 \%$ of the electricity produced in South Africa while the domestic sector consumes only $16 \%$. Only about $36 \%$ of households have access to electricity. Most of these are in the urban areas where approximately $57 \%$ of households are electrified. In the rural areas, which have $40 \%$ of South Africa's population, only $8 \%$ of households have access to electricity. In total, between $65 \%$ and $70 \%$ of the South African population live without a household electricity supply.

Compared to the effectively organised, and efficiently run generation and transmission sectors (Eskom), the distribution sector of the ESI is highly fragmented and 
its operation is the source of many problems in the supply of electricity to end-consumers. The EDI comprises about 430 electricity distributors (DMEA 1992), of which Eskom is the single largest - white local authorities making up the bulk. The fragmentation of the EDI can be explained by the role that local government has historically played in the supply of electricity. The Eskom Act (No. 40 of 1987) and the Electricity Act (No. 41 of 1987) are the two central statutes that govern electricity supply in South Africa at present. Local authorities are not required by the Electricity Act to have a licence to supply in their own areas of jurisdiction and are thus unregulated suppliers in those areas to which they have the first right of supply.

The fragmentation of the EDI has been exacerbated by the racial division of local government. Local authorities in established white areas (WLAs) have well-staffed and -qualified electricity, maintenance and treasury departments. They have wellestablished electricity networks and large capital development funds with few demands for new connections. WLAs have a diversified residential, commercial and industrial customer base with good peak and base load ratios (load factors) and comfortable profits from electricity sales (especially to industrial and commercial consumers) which are used to offset property rates.

The unpopular local authorities in the poorer black areas (BLAs), on the other hand, often do not even have a town electrical engineer. They have underdeveloped technical and administrative capacity with limited access to development capital and a huge demand for new connections. Their existing consumer base is generally small, and consists of residential customers almost exclusively. This results in poor load factors and, as a consequence, higher bulk electricity costs. Their limited revenue from electricity sales is exacerbated by service and rent boycotts, leaving them little capacity to respond to new electricity demand at an affordable cost.

This apartheid-based electricity distribution system has ensured that resources that would enable electrification in the poorer black areas, such as surplus revenue and the ability to raise capital, are locked into the wealthier white areas that are already fully electrified. Local authority electricity undertakings are under direct political control of elected municipal councils. This low-level, racially fragmented political control exacerbates the concentration of resources in wealthy areas.

\section{The need for restructuring}

The political changes in South Africa since February 1990 have enabled the demands for equity in social services to be heard. Access to affordable electricity has become a central component in these demands. The inability of the local government system to supply an affordable service of adequate quality, and to increase access, has contributed to the conflict between township residents and local authority distributors. Electricity supply has been politicised as a result, and in many townships rent and service (including electricity) boycotts have been in effect for years.

An electrification programme aimed at redressing the electrification backlog while keeping up with new household formation will have to reach a connection rate of around 450000 households per year. Such a programme will have an annual average capital expenditure of R1.5 billion. Although electricity distribution was not initially intended to be its central objective, Eskom has recently stepped into the gap left by local authorities. It embarked on a national electrification programme which will reach a connection rate of 200000 houses per year by the end of 1993 . However, Eskom can only electrify those areas that are not controlled by local authorities. Its ability to sustain or expand the programme is thus necessarily constrained by the current structure of the EDI. 
In May 1993 The National Electrification Forum (NELF) was launched to facilitate this process.

\section{Guidelines for restructuring}

The paper argues that the following guidelines should act as the basis for detailed policy proposals.

\section{Govemance:}

\section{Policy:}

- Electricity policy formulation and utility management should be institutionally separated.

- In addition to indirect participation in policy formulation through democratic government, stakeholders should have a direct role in electricity policy formulation and utility supervision.

\section{Ownership:}

- The ESI should remain predominantly in public ownership.

- Stable public-sector governance ensuring long-term financial viability will facilitate access to low-cost finance.

- While remaining in public ownership, utilities should operate as arm's-length commercial corporations.

\section{Regulation:}

- Utilities should be supervised through incentive-based contract plans.

- There should be a national professional regulatory body with powers over the entire ESI.

- The regulator should act pro-actively to inform, mediate and audit the governing processes on the basis of its technical expertise, and effective information systems.

\section{Structure:}

- The changing political and constitutional context in South Africa requires the restructuring of the ESI.

- Generation and transmission investment planning and system operations should be coordinated centrally.

- Distribution should be separated from generation and transmission.

- Distribution should be consolidated into a number of large distributors.

\section{Policy proposals}

Policy proposals will increasingly differentiate between short-term management of the transition and medium-term restructuring goals. Medium-term goals are defined as reflecting the proposed structure for the industry as it should exist after three years. Medium-term and short-term transitional issues are closely related. Decisions about medium-term policy goals give overall direction to short-term policy, while short-term solutions set precedents that could affect, and even foreclose, medium-term options. 
managing the transition are presented. Policy proposals for the structure of the industry are distinguished from those for the governance of the ESI.

\section{Medium-ferm proposals for distribution}

In accordance with the guiding principles determined in the previous chapter, it is proposed that distribution should be institutionally separated from generation and transmission. The currently fragmented distribution industry should be rationalised by establishing a few (less than ten) large distributors. If there are more than one distributors their borders should not coincide with new provincial borders, to avoid subjecting the ESI to potential political tensions that could exist between provincial and national government.

Rural electrification (RE) will be most effectively undertaken by the large regional or national distributors with an internal division responsible for rural electrification. Resource allocation should be formalised and transparent and the RE division should have access to external grant funding. Clear objectives should be set against which performance can be appraised. The RE division should develop specialised methodologies for rural electricity supply that will be built around supporting community participation and ground level institutional development.

\section{Medium-ferm proposals for generation and transmission}

Although generation and transmission lie outside the focus of the EPRET project, some broad pointers to areas that require further investigation are appropriate in this paper.

It is proposed that generation and transmission remain situated in one organisation (currently Eskom) until it becomes desirable to investigate alternative sources of supply. If alternative generation sources, as discussed above, become desirable from a national energy policy perspective, transmission should be separated from generation to ensure impartial grid access and dispatch.

The final decision on the ownership and continued operation of the few municipal coal-fired power stations (about $4 \%$ of national capacity) should be based on economic considerations. Future distributors will probably inherit the municipal power stations and for as long as they have control over these stations the financial relationship between them and Eskom should reflect the true economic value of the generation availability and energy provided by both parties.

\section{Medium-ferm proposals for governance}

Electricity distributors should be established as statutory public corporations in terms of a new electricity act that specifies the rights and obligations of distributors and defines the relationship between distributors, stakeholders, government and the regulator.

A broad outline of the proposed governance framework is provided in Figure 1 and described briefly.

Governance takes place at two levels, namely, energy policy formulation, and utility supervision. National government appoints a stakeholder Energy Policy Council (EPC) in terms of an energy act. The council advises the minister on energy policy, and is responsible for macro-planning to support policy formulation. It reflects these objectives by being structured on two levels. The policy level includes representatives from the Departments of Finance, Mineral and Energy Affairs (DMEA), Development, and others if necessary. It also includes provincial government as well as representatives of key consumer groups and labour. The general planning level is staffed with professionals who are responsible for all the planning and research activities required to support the development and implementation of policy. The EPC will constitute the core of the national energy policy formulation 


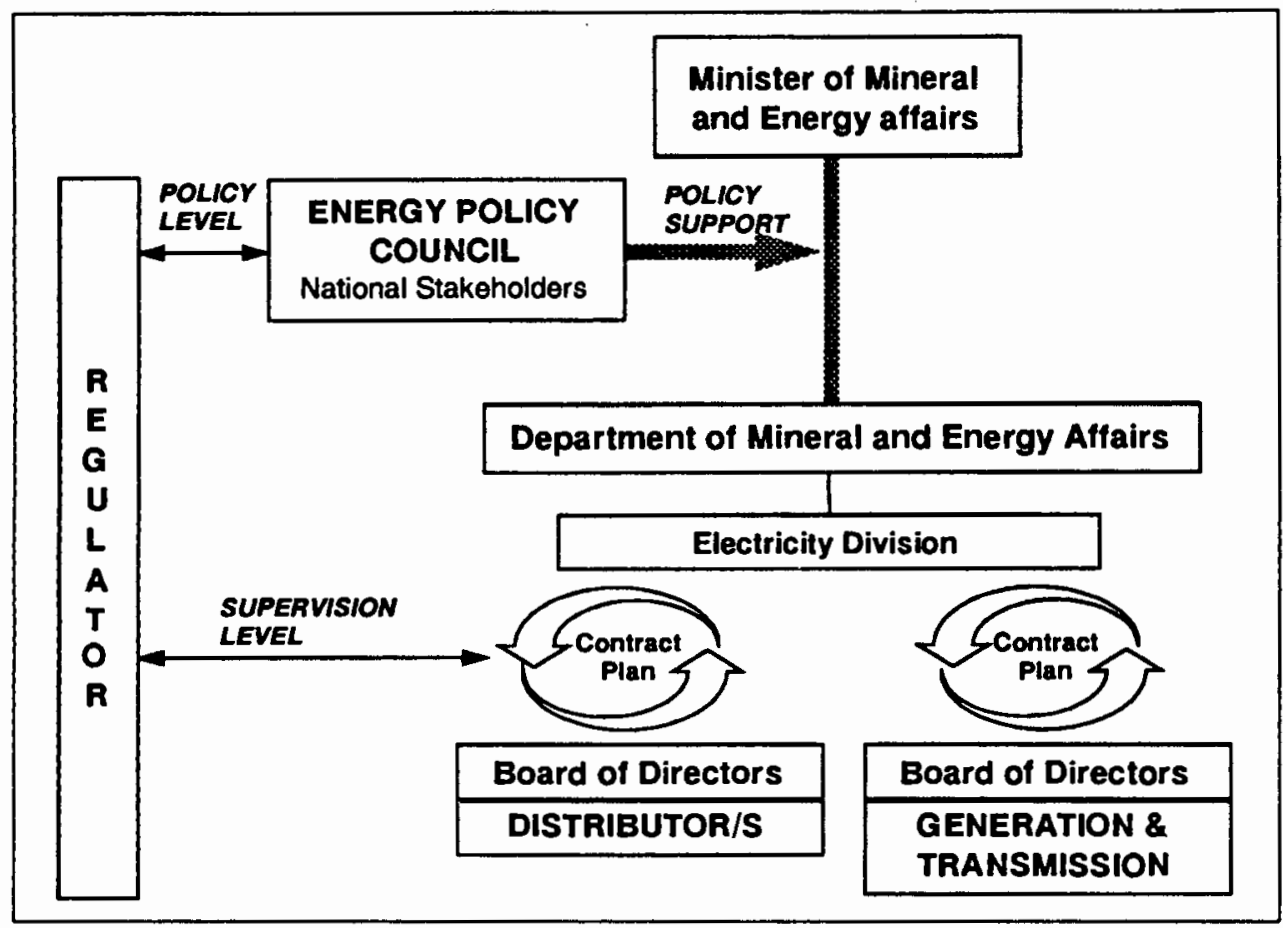

FIGURE 1 The proposed electricity governance framework

process, and will give a high profile to central stakeholders in the energy economy. All governmental energy policy processes should also be obliged to involve the EPC.

The central policy implementation relationship (utility supervision) is embodied in a negotiated contract-plan (CP) agreement between the DMEA, as the administrative representative of government, and the utility board of (mostly executive) directors. The agreement includes a broad range of negotiated performance targets in terms of service and financial parameters. Contract plans are three to five year agreements, but are reviewed annually. The chief executive director is appointed in terms of the agreement. Other executives are appointed by the chief executive, and their appointment is confirmed by the DMEA. Service conditions and re-appointment are based on performance in terms of the $\mathrm{CP}$ agreement.

A national electricity regulator is the custodian of the CP process, and is empowered to act as a referee to ensure unprejudiced CP negotiations.

\section{Managing the transition}

A clear policy for restructuring the ESI, as outlined above, provides an objective for interventions but does not help in any way to deal with the practical complexities of managing the transformation of the current industry. The transition of the ESI will not only have to overcome obstacles to restructuring the industry, but will also have to realise the concurrent objective of accelerated electrification in the context of a changing industry. Obstacles to short-term electrification will have to be overcome before the restructuring of the ESI can be completed.

\section{Key issues for the transition}

Most of the obstacles to transition originate from the specific political, economic, social, and institutional situation in South Africa. These obstacles constitute critical success factors, the neglect of which will seriously affect the success of the transition period. The key issues to be addressed for successful restructuring are the following: 
- whether the powers and functions given to regional government preclude the possibility of implementing national governance functions if required;

- the transfer of local government assets and liabilities;

- the need to alleviate the financial impact of restructuring on local government;

- the need to maintain the financial viability of distributors in the context of rapid electrification;

- the need to apply tariffs that are affordable and legitimate;

- the need to establish a National Electrification Fund to provide distributors with low-cost finance for electrification;

- the need to provide capable distributors with access to unelectrified areas and to ensure that the service is extended to those areas;

- the need to retain the services of professionally skilled and experienced managers to manage the transition of the ESI;

- the need to manage the impact of change on human resources systems;

- the need to coordination electrification with other development processes.

The transition of the EDI can be achieved by mandating NELF to determine policy for the transition, empowering a national electricity regulator to supervise the implementation of policy and by appointing a national transition management, consisting of professional managers, to supervise the transition of the ESI. 


\section{Table of contents}

Executive summary

iii

Table of contents

ix

List of tables

List of figures

Acknowledgements

CHAPTER ONE: Introduction

CHAPTER TWO: The South African electricity supply industry

2.1 Introduction 3

2.2 A history of the development of the electricity supply industry 3

2.3 Domestic electricity supply 6

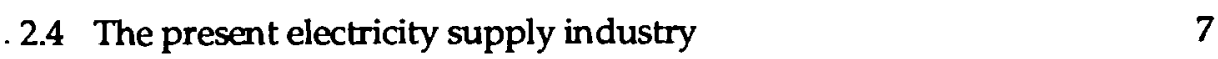

2.5 A national electrification programme 10

2.6 The need for restructuring 12

CHAPTER THREE: Governance and structure $\quad 14$

3.1 Introduction 14

3.2 Governance 14

3.2.1 Energy policy, supervision and utility management 14

3.2.2 Ownership 17

3.2.3 Regulation 22

3.3 Structure 28

3.3.1 Determinants of the ESI structure 28

3.4 General conclusions and guidelines $\quad 30$

CHAPTER FOUR: Policy proposals $\quad 31$

4.1 Introduction 31

4.2 Structure proposals $\quad 31$

4.2.1 Distribution 32

4.2.2 Generation and transmission $\quad 34$

4.3 Governance proposals 35

4.3.1 Ownership 35

4.3.2 Options for the governance framework 35

4.3.3 National Energy Policy Council 37

4.3.4 The institutional roles 38

4.3.5 The contract plan 40

4.3.6 The negotiating process $\quad 40$

4.3.7 Evaluation $\quad 42$ 
5.1 Objectives of transition 44

5.2 Key conditions for the transition 44

5.3 Progress with ESI restructuring 47

5.4 Strategies for the transition 49

5.5 Concluding summary $\quad 50$

References $\quad 51$

\section{List of tables}

Table 2.1 Household access to electricity in $1993 \quad 6$

Table 2.2 End consumers of the six largest electricity distributors 7

Table 2.3 Surpluses generated by the largest distributors 9

Table 2.4 Electrification in South Africa in recent years 10

Table 4.1 The ESI governance process 43

\section{List of figures}

Figure 2.1 Electricity use in South Africa

Figure 2.2 The present operating structure of the South African ESI

Figure 2.3 Annual number of connections needed for a national electrification programme

Figure 2.4 Financing requirement of total electrification programme 11

Figure 4.1 The governance framework for provincial distributors 36

Figure 4.2 The proposed electricity governance framework

\section{Acknowledgements}

I would like to acknowledge the support and guidance provided by Anton Eberhard, Paul Theron and Gordon MacKerron during the research and writing of this paper. 


\section{CHAPTER ONE}

\section{Introduction}

South Africa is undergoing fundamental political and constitutional change that will, for the first time, bring democracy to this country. After years of apartheid discrimination, a democratic government will be faced with massive demand for the delivery of social services. The electrification of homes will feature high on the list of national priorities.

The national social infrastructure, including the electricity supply industry (ESI), has developed, under decades of apartheid rule, to serve the interests of the white minority. Even the very basic needs of the poor, such as the provision of adequate shelter, clean water, sanitation and energy, have not been fully met. Most South Africans do not have access to domestic electricity and, in its current fragmented form, the ESI will not be able to fulfil the need for rapid electrification. This paper analyses the problems associated with the present ESI and develops a proposal for the restructuring of this industry.

Internationally, both developed and developing countries are wrestling with three sets of long-term development objectives:

a) to promote the growth and international competitiveness of their economies;

b) to provide social equity for all the members of their societies; and

c) to ensure the sustainability of their interactions with the natural environment.

These objectives will have to guide the endeavours of the South African economy as a whole and the electricity supply industry specifically. They will present significant challenges for the ESI:

a) to supply electricity of an appropriate quality and with tariffs that promote economic efficiency;

b) to provide access for the poor and fulfil their basic energy needs; and

c) to protect the environment for future generations.

Problems with the performance of the power sector in developed and developing countries in recent years, have prompted new debates about the appropriate organisation of the industry. In developed countries, the scope for efficiency improvements through technological developments has become limited. The focus has shifted to the potential for changes in the governance structure to achieve further improvements in in dustry performance. Managers are now being provided with performance incentives through new forms of regulation and the introduction of competition into the power sector.

In less developed countries a direct 'command and control' type of governance resulted in prices that were too low, and in a drastic weakening of the financial position of utilities. As a result utilities were often not able to raise capital to expand their capacity to supply a growing demand for electricity. In the worst cases, utilities were not able to obtain foreign currency to obtain spare parts for basic maintenance. Problems with poor quality of supply, brown-outs and black-outs are widespread in developing countries. Multilateral agencies, such as the World Bank, and research organisations, such as the Cooperative Programme for Energy and Development (COPED), are involved in ongoing research and debate to develop policies for the reform of the power sector in developing countries. 
South Africa has unique opportunities in the electricity sector to supply low-cost electricity to a growing economy, and to provide access to electricity for most of its population: it has large surplus generating capacity on the national grid and generates the second cheapest electricity in the world; it has the skills and systems to implement a large electrification programme; and most of its citizens earn on average higher incomes than in most other African countries, and live in dense settlements that will be relatively cheap to electrify. Provided that institutional problems in the electricity distribution industry can be solved, these circumstances provide an unique opportunity for low-cost household energy supply. Policies for the restructuring of the ESI should be aimed at enabling the industry to implement a national electrification programme while simultaneously maintaining a low cost electricity supply to an economy that could experience considerable growth in the next decade. In the context of a newly established populist democracy, policy proposals should specifically aim to avoid the problems experienced by the ESIs of other developing countries, by establishing a system of governance that will ensure the viable management of the ESI through the careful balancing of the objectives of public policy with the imperatives of a viable industry.

The scope of the research was initially limited to the electricity distribution industry. But, the quest for equity in service delivery and efficiency improvements in power system operations and expansion is directly influenced by the interrelated nature of modern interconnected power systems. The investigation was thus extended to the electricity supply industry in its entirety, while maintaining a focus on the distribution of electricity. Both the structure and the governance of the ESI are discussed, but emphasis is placed on issues related to governance. Questions affecting the relationship between the state and the ESI, such as policy formulation, regulation, utility supervision and ownership, thus receive particular attention.

Chapter Two discusses the problems of the present ESI and briefly reviews the industry's historical development. In Chapter Three, relevant international experience is drawn on to develop a theoretical framework that enables the formulation of guidelines for the structuring of a future ESI. The fourth chapter builds on these guidelines in order to develop a specific proposal for the future structure and governance of the ESI. In the last chapter considerations for managing the transition of the ESI are discussed. 


\section{The South African electricity supply industry}

\subsection{Introduction}

The current organisation of the South African electricity supply industry (ESI) and the pattern of unequal domestic access to electricity is the result of a historic process that is closely tied up with the development of the South African economy and the apartheid state.

This chapter provides a background to the debate on the restructuring of the ESI. It starts out with a brief discussion of thehistorical development of the ESI, followed by a description of present electricity supply patterns and a review of the industry's structure and governance. The section that follows discusses the nature and scale of a proposed national electrification programme. In conclusion, the need for restructuring, and the initiatives currently being undertaken to achieve this, are discussed.

\subsection{A history of the development of the electricity supply industry}

A review of the historical development of the ESI enables a clearer understanding of the problems currently associated with the industry.

Municipalities took the lead in supplying electricity in South Africa. Shortly after the discovery of diamonds in Kimberley, the first electric street lights were switched on in this growing mining town in 1882. Kimberley municipality established its own reticulation service in 1890, Johannesburg in 1891, Pretoria in 1892, Cape Town in 1895, Durban in 1897, East London in 1899 and Bloemfontein in 1900 (de Villiers 1984). The discovery of gold on the Witwatersrand in 1886 , and the subsequent development of the mining industry, required the generation of electricity on a more extensive scale. After the Anglo-Boer War (1899-1902), the demand for electricity by the mining sector rose sharply. Mining companies established a number of independent power stations in Kimberley and on the Witwatersrand. The largest was the Victoria Falls Power Company which was registered in October 1906. In 1909 it changed its name to the Victoria Falls and Transvaal Power Company (VFTPC) (Horwitz 1993).

The development of the ESI can be split into four distinct periods (Horwitz 1993). From 1906 to 1922, the industry consisted of a mixture of private and municipal enterprises. After 1922, a national public body, the Electricity Supply Commission (Escom), co-operated with the private and municipal suppliers. After 1948 Escom took over the Victoria Falls and Transvaal Power Company, thereby essentially monopolising the generation and transmission of electricity. In 1985, Escom underwent a major restructuring after a period of poor performance.

Early legislation dealing with electricity supply focused on minimum safety standards (Morgan 1993a). The earliest law dealing with electricity supply was probably the Municipal Corporations Lighting Law, Natal, No. 22 of 1891 (Morgan 1993a). Shortly after the Anglo-Boer War, legislation was enacted in the Transvaal, Cape Colony and the Orange Free State that subjected the supply of electricity to the consent of local authorities and the colonial administrator. This principle of local government and provincial level (previously colonial) control has survived up until the present time. 
In 1909, the Power Companies Commission, set up to 'enquire into the desirability of the establishment of large electric power companies in the Transvaal", reported that the supply of electric power should as far as possible be left to private enterprise. However, noting that 'the supply of electricity leads to a virtual monopoly in [the supply of] a commodity which has become practically a necessity of modern civilisation", the commission recommended that electricity supply should be placed under government control to ensure the equitable supply of power, public safety and the public interest in general (Morgan 1993a).

In 1910 the Transvaal Colonial Government passed the Power Act of 1910 to effect the recommendations of the Power Companies Commission. The Act stipulated that an electricity undertaking could only be established under a licence issued by the Minister of Mines. It established a Power Undertakings Board, consisting of public officials, that acted in an advisory capacity to the Minister. Municipalities were not required to have a licence and were thus not controlled by the Board and the Minister. Undertakings applying for a licence had to submit a schedule of standard prices together with the application. The Minister was obliged to refer a licence application to the Board, which held public hearings on the application before advising the Minister on whether the application should be granted or refused. Members of the public were thus given the opportunity to object to the licence application. The Act also specified that companies had to pay all consumers twenty five per cent of their 'surplus profits' at a rate pro rata to their electricity consumption. This principle remained the accepted manner of regulating licensed power companies in the Union of South Africa until the passing of the Electricity Act of 1922 (Horwitz 1993).

The South African Railways and Harbours Administration (SAR\&H) played an important role in the development of the ESI as a result of their need to electrify the railways. The SAR\&H commissioned a London firm of consulting engineers, Merz and McLellan, 'to study the general question of electric power supply' (Morgan 1993a). Their report, entitled 'Electric Power Supply in the Union of South Africa' was presented in April 1920. This report reflected concern about the uncoordinated development of the ESI, which could potentially impose a high cost on future industrial development. It led to the promulgation of the Electricity Act No 42 of 1922 by the Government of the Union, which established the Electricity Supply Commission (Escom) and the Electricity Control Board (ECB). Escom's primary mandate was to establish new electricity undertakings and to co-operate with existing undertakings so as to ensure a cheap and abundant supply of electricity. Escom was supposed to supply electricity 'neither at a profit nor at a loss". The Electricity Control Board was established to control the supply of electricity by the Commission and private undertakings. The Act stipulated that the supply of electricity could not be undertaken without a licence issued by the Board. Escom and private undertakings were thus obliged to apply for licences, but local authorities and government departments (including the SAR\&H) were once again exempted. The Act also included the profit sharing stipulations introduced by the Transvaal Power Act of 1910.

Escom grew steadily as the bulk supplier of electricity. In 1948 Escom purchased the VFTPC after complaints from the mines about excessive profit-taking, despite the 'automatic' profit rebate system (Horwitz 1993). By finally taking over the VFTPC, Escom established itself as a national public monopoly electricity generator. The take-over coincided with the rise of Afrikaner Nationalism and the election of a Nationalist government.

In 1957 the Electricity Act was translated into Afrikaans and incorporated with all its amendments into a new Act, the Electricity Act No. 40 of 1958. In 1971 the Electricity Amendment Act, No. 49 of 1971, was passed to allow for the establishment of a Capital Development Fund. This Act also allowed the different regional undertakings to be connected to allow the Escom power stations to be run 
as an integrated system. By 1973, all the separate Escom undertakings were linked by the national grid.

Up until the mid 1970s, Escom progressed successfully as the central electricity supply organisation. It enjoyed the benefits of improving technology and continued demand growth. Towards the end of the 1970s, inflation, higher financing costs and the reduced financial returns of new technology contributed to poor performance and high tariff increases (De Villiers 1984). These problems, together with the high proportion of South African foreign debt that was attributable to Escom, prompted the State President to appoint the 'Commission of Inquiry into the Supply of Electricity in the Republic of South Africa' (1984) under the chairmanship of Dr W $\mathrm{J}$ de Villiers. De Villiers recommended that a two-tier control structure be introduced, consisting of a board of control and a management board, and that the principle of operating neither at a profit nor a loss be discarded in favour of a sound assets and income structure. It was also proposed that the concept of different undertakings within Escom be discarded and allowance made for the pooling of costs. This meant that the tariffs for different consumer classes could be built up from national mean pooled costs.

These recommendations should be read in the context of the government's interest in privatising Escom and other parastatals at that time (Horwitz 1993). Many of the De Villiers recommendations were given effect to in 1985 and 1986 when the Electricity Act of 1958 was amended. The 1985 amendment restructured the Electricity Supply Commission by establishing the Electricity Council whose tasks were to determine policy for Escom and appoint and oversee the management board. The Electricity Council was to consist of stakeholders and independent experts and was supposed to operate in the manner of a board of directors for a company in the private sector.

The Electricity Act of 1958 was repealed by the Electricity Act of 1987. The new Act provided for the continued existence of the Electricity Control Board. It also exempted Local Authorities (when supplying within their area of jurisdiction), self-governing territories and Eskom from requiring a licence to supply electricity. The Eskom Act of 1987 consolidated all the amendments to the Electricity Act with regard to Escom, and changed the spelling of the name to Eskom.

De Villiers improved the management of Eskom and ensured that the interests of industry, commerce and white municipalities were represented on the Electricity Council. The commission did nothing to change the lot of black households, most of whom were still without any electricity connection.

In metropolitan areas, white local authorities traditionally supplied some adjacent black townships with electricity. In 1973, however, Bantu Administration Boards were established to take over the supply of services to the black townships. These Boards did not have access to the revenue base of the wealthier white local authorities, which incorporated local industry and commerce. The immediate consequence was a decline in the standard of service to black townships, and an inability to extend services. In the early 1980s, with the passing of the Black Local Authorities Act (No 102 of 1982), service provision was taken over by the black local authorities. This change precipitated the current crises in service provision (including electricity) to black areas. 


\subsection{Domestic electricity supply}

South Africa has a total net generating capacity of about $37000 \mathrm{MW}$ and in 1992 produced 149427 GWh of electricity (Eskom 1993a). The percentage of electricity use per sector during 1990/91 is illustrated in Figure 2.1.

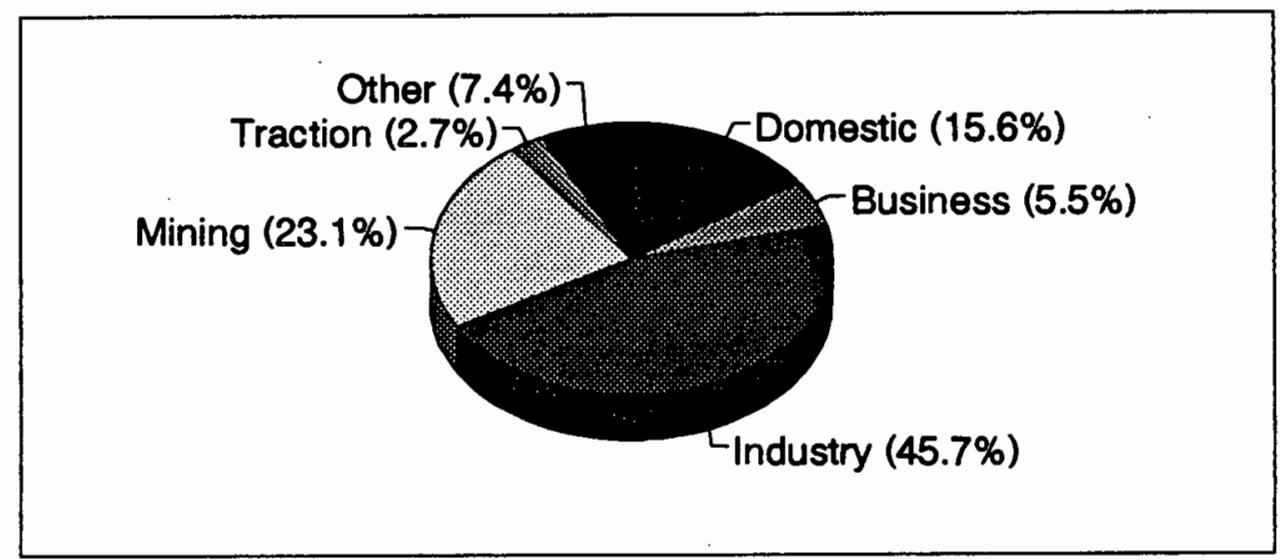

FIGURE 2.1 Electricity use in South Africa Source: Compiled from Eskom (1993b)

Figure 2.1 shows that mining and industry consume just under 70 per cent of the electricity produced in South Africa, while the domestic sector consumes only 16 per cent. Total annual domestic electricity consumption is in the region of 23310 GWh. Table 2.1 shows the proportion of rural and urban households which have access to electricity.

\begin{tabular}{|l|c|c|}
\hline \multicolumn{1}{|c|}{ Dwellings } & Number in category & Percentage electrified \\
\hline RURAL & 3500000 & 6 \\
\hline Farmworkers & 900000 & 15 \\
Dense settlements & 1300000 & 4 \\
Scattered settlements & 1300000 & 1 \\
\hline URBAN & 5300000 & 57 \\
\hline Informal unplanned & 500000 & 0 \\
Intormal planned & 600000 & 12 \\
Backyard shacks & 700000 & 17 \\
Formal low-income & 1400000 & 41 \\
Formal mid-high income & 2100000 & 100 \\
\hline TOTAL & 7600000 & 36 \\
\hline
\end{tabular}

TABLE 2.1 Household access to electricity in 1993 Source: NELF Database (1993)

Only about 35 per cent of households have access to electricity in South Africa. Most of these are in the urban areas where approximately 54 per cent of households are electrified. In the rural areas, which hold 40 per cent of South Africa's population, only six per cent of households have access to electricity. In total, between 65 per cent and 70 per cent of all South Africans live without a household electricity supply.

The low levels of household electricity supply, slow progress with electrification and other problems related to the supply of electricity, such as the more than 1100 different domestic tariffs that are applied (AMEU 1993), are closely related to the institutional fragmentation of the electricity distribution industry (EDI). These problems are discussed in more detail below. 


\subsection{The present electricity supply industry}

The operating structure of the ESI can be divided along functional lines into three sectors: generation, transmission and distribution. Bodies undertaking the generation of electricity from thermal, nuclear and hydro sources form the generation sector. The transmission sector is made up of the bodies that undertake the highvoltage bulk transmission of electricity from the generation source to the distribution utilities. Distributors that are responsible for the final supply to end users fall into the distribution sector. The operating structure of the South African ESI is illustrated in figure 2.2

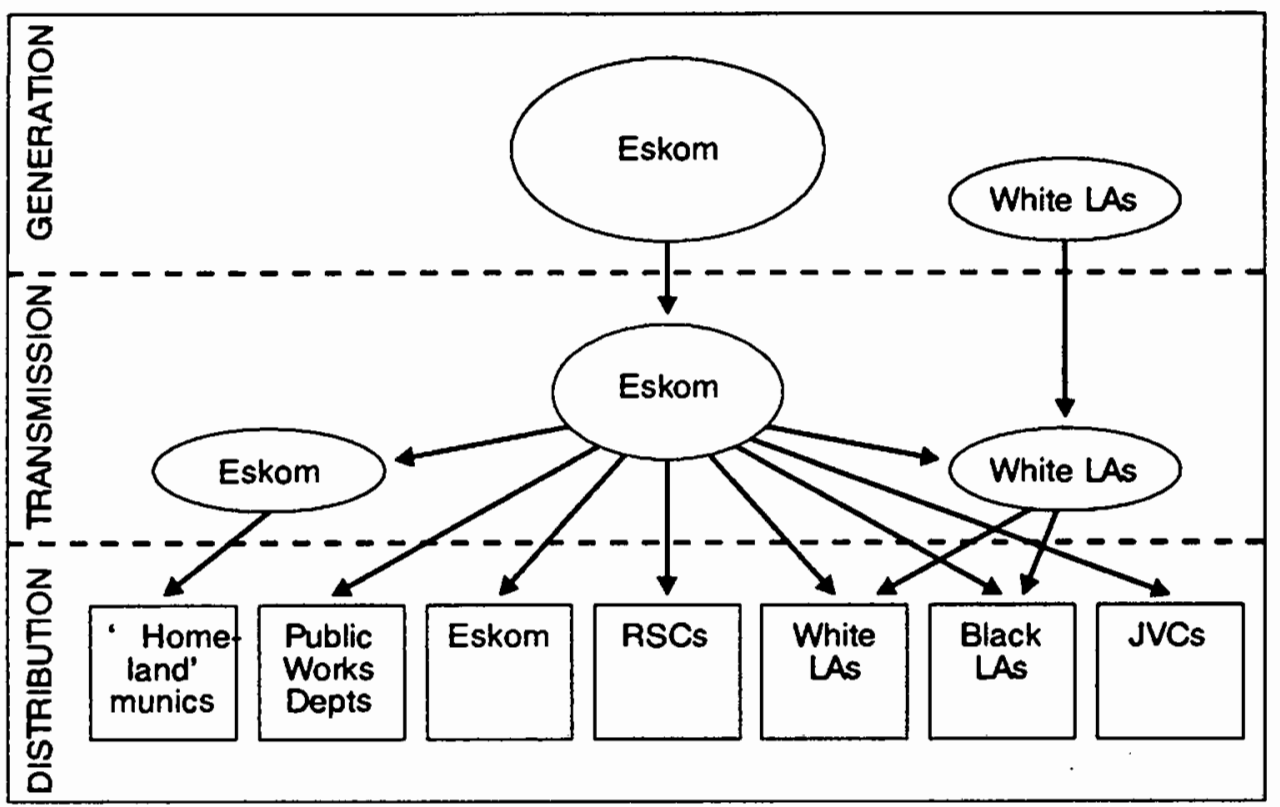

FIGURE 2.2 The present operating structure of the South African ESI Source: Steyn \& Theron (1992)

Eskom supplies 98 per cent of all the electricity generated in South Africa from power stations that are mostly situated in the Eastern Transvaal Highveld. Some of the larger municipalities, such as Cape Town, Port Elizabeth and Johannesburg operate small power stations. Most of the municipal power stations are used as a backup to the Eskom system and run only occasionally (except in the case of Johannesburg, which has ready access to very cheap coal). Eskom has large surplus generating capacity and provides bulk tariff incentives for municipalities not to operate their own stations. Eskom owns and operates the national integrated transmission network that transmits high-voltage bulk electricity to all its large consumers, including the distributors.

Compared to the effectively organised, and efficiently run generation and transmission sectors, the distribution sector is highly fragmented; its operation is the source of many problems in the supply of electricity to end consumers. The EDI in South Africa comprises of about 430 electricity distributors (DMEA 1992). Eskom is the single largest distributor and white local authorities (WLAs) make up the bulk of the distributors. There are a host of smaller distributors as well, mostly black local authorities and homeland electricity supply corporations, homeland Departments of Works and homeland municipalities. A few Regional Services Councils and joint venture companies (JVCs), established by Eskom, also supply electricity to end users.

Table 2.2 shows that the largest six distributors serve nearly half of the total number of consumers. About 351 ( 90 per cent) of the remaining distributors have less than 10000 consumers and 209 have less than 1000 consumers (DMEA 1992: 21). 


\begin{tabular}{|l|c|c|r|r|r|r|}
\hline \multicolumn{1}{|c|}{ Distributor } & Domestic & Famming & Commercial & Industrial & \multicolumn{1}{c|}{ Other } & \multicolumn{1}{c|}{ Total } \\
\hline Eskom & 397588 & 122112 & 17925 & 2652 & 1602 & 541879 \\
\hline Durban & 258000 & - & 30000 & 550 & - & 288550 \\
\hline Cape Town & 223000 & - & 16300 & 500 & 127 & 239927 \\
\hline Pretoria & 132000 & - & 4400 & 446 & 5300 & 142146 \\
\hline Johannesburg & 122000 & - & 7600 & 4400 & - & 134000 \\
\hline Port Elizabeth & 64000 & - & 6200 & 640 & 1 & 70841 \\
\hline Subtotal & 1196588 & 122112 & 82425 & 9188 & 7030 & 1417343 \\
\hline Others & 1182000 & 7000 & 93550 & 15300 & 42500 & 1358000 \\
\hline TOTAL & 2378588 & 129112 & 175975 & 24488 & 49530 & 2775343 \\
\hline
\end{tabular}

TABLE 2.2 End consumers of the six largest electricity distributors Source: Adapted from DMEA (1992) and Eskom (1993)

The present fragmentation of the electricity distribution industry (EDI) can be explained by its fragmented governance, and specifically by the role that local government has played historically in the supply of electricity. The Eskom Act (No. 40 of 1987) and the Electricity Act (No 41 of 1987) are the two central statutes that govern electricity supply in South Africa at present. The Electricity Act requires distributors to operate under a licence issued by the Electricity Control Board. But the Act exempts both local authorities supplying in their areas of jurisdiction and Eskom from the licensing requirement. Local authority councils thus have first right of supply in their areas of jurisdiction, and have full control over most policy matters (including tariffs) in their areas. In terms of the Eskom Act, Eskom is authorised to generate and supply electricity in South Africa subject to the rights of local authorities and licence holders. Although the Electricity Council determines Eskom's tariff levels, the Electricity Control Board has final jurisdiction over Eskom's tariff structures.

The fragmentation of the EDI has been exacerbated by the racial division of local government. Local authorities in established white areas (WLAs) have well-staffed and qualified electricity, maintenance and treasury departments. They have wellestablished electricity networks and large capital development funds, together with few demands for new connections. WLAs have a diversified residential, commercial and industrial customer base, with good peak and base load ratios (load factors) and comfortable profits from electricity sales (especially to industrial and commercial consumers), which are used to off-set property rates.

On the other hand, the unpopular local authorities in the poorer black areas (BLAs) often do not even have a town electrical engineer. They have underdeveloped technical and administrative capacity, together with limited access to development capital and a huge demand for new connections. Their existing consumer base is generally small, and consists almost exclusively of residential customers. This results in poor load factors, and as a consequence, higher bulk-electricity costs. Their limited revenue from electricity sales is exacerbated by service and rent boycotts, leaving them little capacity to respond to new demands for electricity at an affordable cost.

Local authority municipal departments are under the direct political control of elected municipal councils. This low-level, racially-fragmented political control has ensured that resources that would enable electrification in the poorer black areas, such as surplus revenue and the ability to raise capital, are locked in to the wealthier white areas that are already fully electrified.

The financial position of local authority electricity distributors varies widely. The larger white local authorities with a significant commercial or industrial consumer base are generally in strong financial positions, and traditionally generate surpluses 
in excess of ten per cent of gross revenue. The largest part of this surplus is usually transferred to the rates account to provide relief to property rates by cross-subsidising 'non-tradable' services. Table 2.3 shows the surpluses generated by the six largest municipal electricity undertakings.

\begin{tabular}{|l|c|c|c|c|}
\hline \multicolumn{1}{|c|}{ Distributor } & $\begin{array}{c}\text { Financial } \\
\text { year-end }\end{array}$ & $\begin{array}{c}\text { Balance sheet } \\
\text { value } \\
\left(R^{\prime} \text { '000) }\right.\end{array}$ & $\begin{array}{c}\text { Actual } \\
\text { surplus } \\
\left(R^{\prime} \text { '000) }\right.\end{array}$ & $\begin{array}{c}\text { Actual surplus } \\
\text { as \% of total } \\
\text { revenue (\%) }\end{array}$ \\
\hline Durban & 1992 & 1295232 & 114662 & 11.70 \\
\hline Johannesburg & 1992 & 955389 & 215833 & 23.07 \\
\hline Cape Town & 1992 & 798154 & 92571 & 15.95 \\
\hline Pretoria & 1993 & 494257 & 178766 & 21.40 \\
\hline Port Elizabeth & 1993 & 316450 & 27028 & 11.04 \\
\hline Bloemfontein & 1992 & 269322 & 19633 & 15.86 \\
\hline
\end{tabular}

1. In addition to the surplus of income over expenditure, the actual surplus includes services provided free, such as public lighting, traffic lights, electricity supply to other departments, and the rental of land and buildings for other departments.

TABLE 2.3 Surpluses generated by the largest distributors Source: Adapted from the NELF supply side database (1993)

White local authorities obtain most of their income from property rates and surpluses on tradeable services, and receive very little support in the form of fiscal transfers from first- or second-tier government. Many are thus dependent on the surpluses transferred from the electricity account. In 1992 a total of R1.3 billion rands (NELF 1993) was transferred from municipal electricity undertakings to other municipal accounts. Any restructuring of the ESI that will affect the surplus transfers will thus have to coincide with a restructuring of national fiscal transfers.

Municipal distributors probably also conceal large inefficiencies. The proliferation of distribution authorities has resulted in a situation where there are often more than ten (and sometimes up to twenty) distributors in a metropolitan area. Uncoordinated capital expenditure has resulted in the costly duplication of electricity networks. There is also often duplication of operating and maintenance infrastructure, such as control rooms and workshops. In the municipal sector, all co-ordination of research-and-development and technological standardisation is on a voluntary basis and is thus limited.

Inefficiencies also result from the system of direct political governance that municipal electricity undertakings are subject to. Municipal tariffs are set at levels which will generate surpluses. They are not based on long-run marginal costs, and often do not even reflect average costs. Pricing signals will thus result in inefficient consumer behaviour. The management of local government electricity departments generally have a close relationship with local government politicians. All major policy decisions (including electricity pricing) have to be approved by the elected municipal council. When attending industry-related conferences, for instance, management is often accompanied by a local government councillor. This direct political command and control relationship is bound to result in poor and inefficient management practices. The municipal electricity sector is, for instance, largely oblivious to the advances over the last fifteen years in management theory, which aims to increase organisation efficiency through measures such as management by objectives, performance measurements through performance indicators, performance-related human resources management and an emphasis on customer-focused marketing activities.

Generally, the direct command and control governance of municipal electricity undertakings prevents a commercial focus, and renders them unattractive to 
professional managers. This results in poor customer care and inefficiencies in operation and investment.

South Africa's constitutional restructuring will result in the amalgamation of apartheid-based local government in both urban and rural areas in terms of the Local Government Transitional Bill (B 214-93 (GA)) of 1993. Electricity departments, along with other bulk-services departments, will be partly rationalised in this process, but restructuring of local government will do nothing to improve the governance of electricity.

\subsection{A national electrification programme}

The development of the ESI has been shaped by South Africa's political economy. Particular social formations have controlled state power and hence the allocation of investment resources. Public enterprises have served the needs of industry and those of the enfranchised minority well, while the needs of the disenfranchised have largely been neglected. As government is democratised, the material interests of a wider range of social formations will inevitably be expressed in macro-economic policies which give greater emphasis to redistributive in vestment. Priority will be given to achieving greater equity in the provision of basic services, and the EDI will no doubt be given a much clearer mandate to extend access to affordable electricity supplies.

A review of the scale of an electrification programme required to supply most households with an electricity connection gives an indication of the demands that will be made of the ESI over future years.

The best available information on the rate of electrification in recent years is shown in Table 2.4 .

\begin{tabular}{|l|c|r|r|c|}
\hline & 1990 & 1991 & \multicolumn{1}{|c|}{1992} & 1993 \\
\hline Eskom & 31035 & 31000 & 158000 & 199000 \\
\hline Other (mostly municips.) & 43000 & 110843 & 72347 & 104465 \\
\hline TOTAL & 74035 & 141843 & 230347 & 303465 \\
\hline
\end{tabular}

TABLE 2.4 Electrification in South Africa in recent years Source: Eskom

Although Eskom had attempted to step up their electrification drive in previous years, it had only really took on significant proportions by 1992, with 158000 new connections. Eskom will not be able to sustain this rate of electrification because the municipalities hold the supply rights to most residential areas, and Eskom will thus soon rum out of areas to connect.

Recently,significant research effort has been devoted to the appropriate nature of a national electrification programme that will supply the majority of South African households with electricity. The National Electrification Forum's National Electrification Economic Study (NEES) has drawn on research by Eskom and the Energy for Development Research Centre (EDRC) at the University of Cape Town, in order to develop scenarios for a national electrification programme. A brief review of the most likely scenario for the electrification programme will give an indication of the demands that will be placed on the ESI over the next twenty years.

As indicated in Figure 2.3, the rate of connections is projected to rise to 450000 per annum in order to keep up with the rate of new household formation and to make up the backlog. Such a sustained programme will achieve 70 per cent household access over a decade and 80 per cent household access over twenty years. 
Based on realistic assumptions about the cost of connections, consumption growth, operating and maintenance costs and a four per cent real discount rate, it is calculated that, with a tariff employing a single energy rate of $18 \mathrm{c} / \mathrm{kWh}$, the programme will have a maximum cumulative financing requirement of R28.0 billion (in 1993 rands) (NEES 1993: 12). Figure 2.4 shows the annual and cumulative financing requirements for the programme inclusive of both the operating and capital costs.

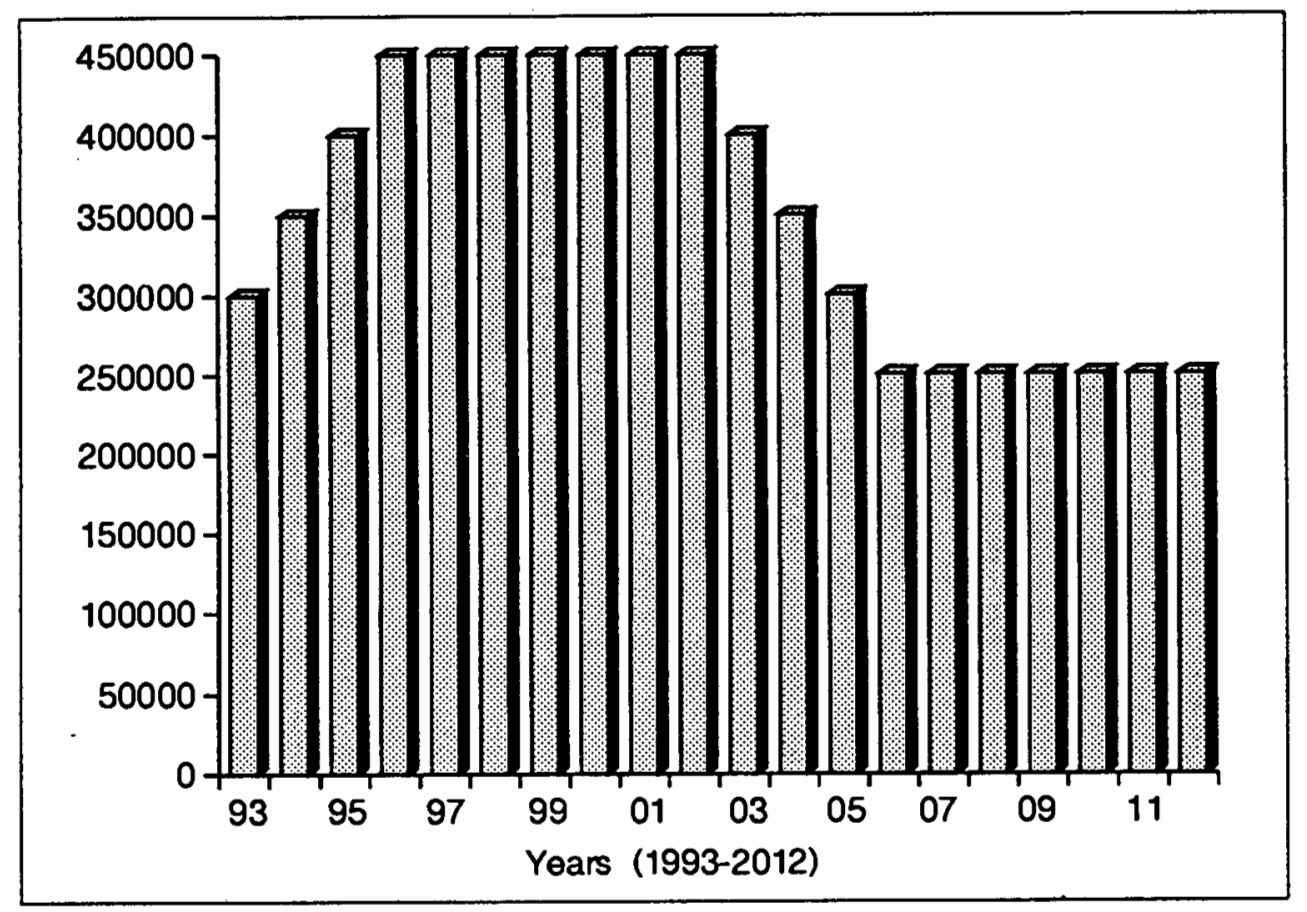

FIGURE 2.3 Annual number of connections needed for a national electrification programme Source: NEES (1993)

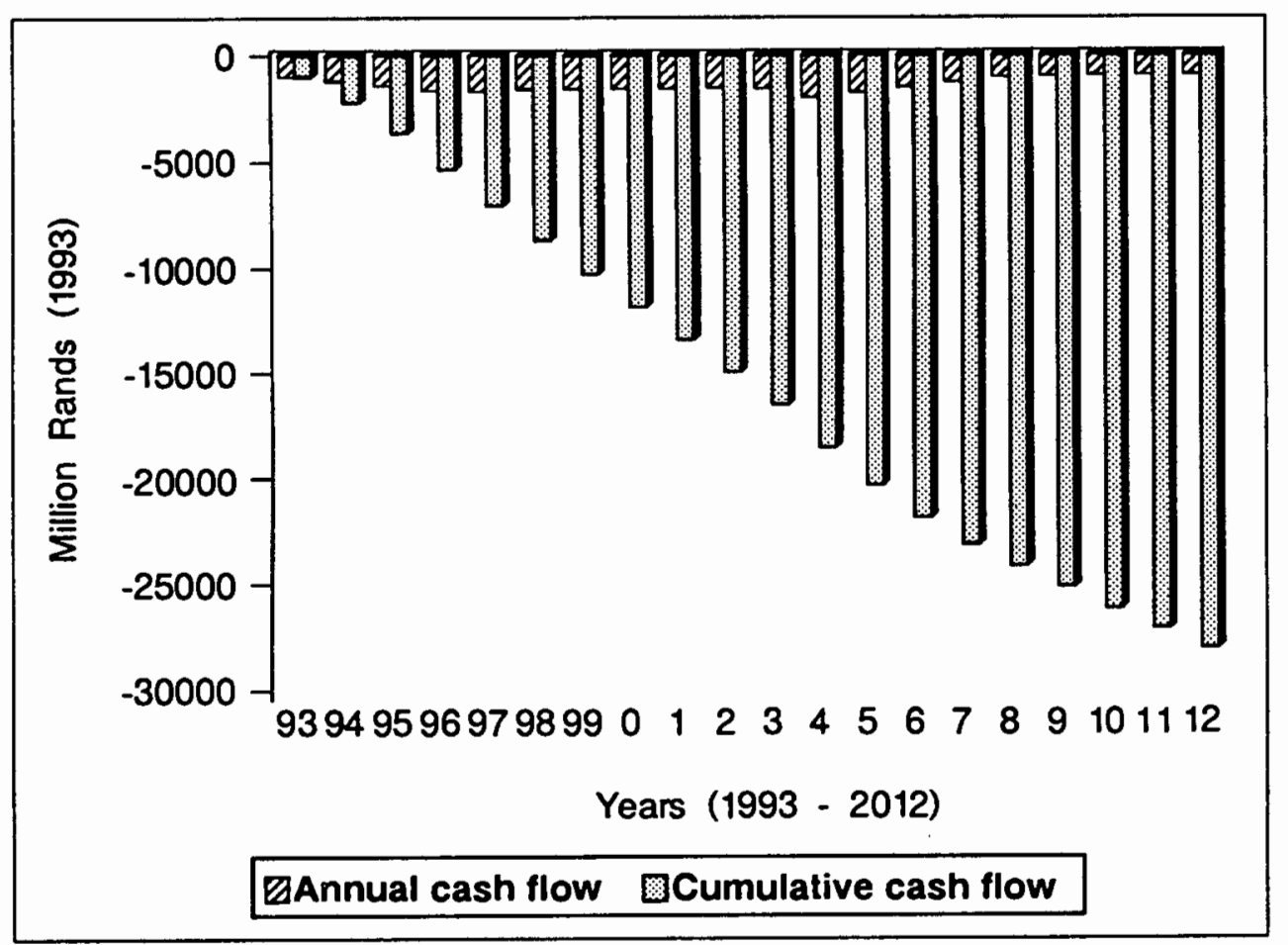

FIGURE 2.4 Financing requirement of total electrification programme 
Average annual capital expenditure is R1.5 billion per annum, and will peak at R2 billion around the twelfth year of the programme. The operating cash flow turns positive after about 13 years. The operating cash flow for the rural part of the programme remains negative throughout the programme, but it will be smaller that the operating surpluses that are incurred in urban areas towards the latter half of the programme.

Many options for financing the programme exist. Van Horen (1994) identified the significant role that a financing contribution from the existing domestic consumer base can play. If, for example, all domestic tariffs could be rationalised to an average level of $18 \mathrm{c} / \mathrm{kWh}$, as assumed above, the potential additional financing contribution from the existing formal mid-high income consumer class will be more than R400 million per year. It is also possible to cross-subsidise the electrification programme from other consumer classes by redirecting the present surplus transfers back to the ESI. In addition, South Africa has well-developed financial markets, and the ESI (Eskom in particular) raises finance on the open capital market on an ongoing basis. Grant and subsidy finance will also remain important sources of funding for electrification in the future.

The institutional structure and governance framework of the ESI will affect the extent to which these financing opportunities can be exploited. In the following chapters it will be demonstrated that the need to ensure the sustainable financing and implementation of a national electrification programme will be an important guideline for ESI restructuring.

\subsection{The need for restructuring}

The political changes in South Africa since February 1990 have enabled the demands for equity in access to social services to be heard. Access to affordable electricity has become a central component of these demands. The inability of the local government system to supply an affordable service of adequate quality, and to sufficiently increase access, has contributed to the conflict between township residents and local authority distributors. As a result, electricity supply has been politicised, and in many townships rent and service (including electricity) boycotts have been in effect for years. Although electricity distribution was not initially intended to be its central objective, Eskom has recently stepped into the gap left by local authorities. However, Eskom can only easily gain access to those areas that are not controlled by local authorities. It requires the consent of the relevant local authority to supply electricity within its area of jurisdiction in terms of the Electricity Act. The Remuneration of Town Clerks Act (No. 115 of 1984) links the remuneration of local authority officials to the grading of the local authority, which is in turn linked to the number and level of services provided by the local authority. Local authority officials thus have an incentive to resist handing over the supply of electricity to another body. Eskom's ability to sustain or expand the programme is thus necessarily constrained by the current structure of the EDI.

These institutional constraints have led to calls for the industry to be restructured. As early as 1983 the Institute for Municipal Treasurers and Accountants 'supported the concept of the regional supply of electricity, in a memorandum to the United Municipal Executive' (DMEA 1992: i). In October 1990, the Permanent Finance Liaison Committee (PFLC) of the Department of Finance appointed a working group to investigate the possibility of distributing electricity on a regional basis (PFSK: 1991). This working group produced an interim report that was approved by the PFLC in November 1991 (Venter 1992). In February 1991, the Minister of Mineral and Energy Affairs requested the then National Energy Council to 'make recommendations on suitable future orientated organisational structural models for the electricity distribution industry, including the identification of legislation 
that may be necessary, implementation and other considerations' (DMEA 1992).

The National Energy Council became the Energy Branch of the Department of Mineral and Energy Affairs (DMEA) in April 1992. The work of the PFLC-working group and the DMEA was closely co-ordinated at the request of the South African Cabinet. The results of both these investigations were published together in 1992 (DMEA 1992). The report concluded that significant efficiency gains could be achieved by rationalising the distribution industry and recommended the '... development of a small number (between 5 and 15) of regional single service (electricity only) distributors on an evolutionary basis", to take over most of the current distribution undertakings (DMEA: $\mathbf{x i}$ ).

At an African National Congress national meeting on electrification in Cape Town in February 1992, a call was made for a widely representative national electrification forum to address the need for accelerated electrification and industry restructuring (Theron 1992). The National Electrification Forum (NELF) was launched on 14 May 1993 at a national electrification conference in Johannesburg. The NELF represents all stakeholders in the supply of electricity and has a plenary, a management committee, a secretariat and working groups. Presently there are working groups on:

- regulatory framework, structure and policy;

- human resources;

- supply technology, standards and RAPS;

- ESI database;

- financing and tariffs;

- facilitation of the transition process of the distribution industry; and

- end-use of energy and the environment

The NELF has become the centre for negotiations concerning the restructuring of the ESI. The management committee has initially set itself the target of reaching consensus on a proposed model for restructuring the industry by the end of November 1993, but by January 1994 they had not yet succeeded in their objective. 


\section{Governance and structure}

\subsection{Introduction}

Electricity is an essential input to modern social and economic development. The success of the electricity supply industry (ESI) depends on how effectively electricity provision supports social and economic development objectives, as defined and prioritised by government policy. In a post-apartheid era, South Africa's public policy is likely to be characterised by the pursuit of competitiveness, sustainability and equity, especially.

The objective of this chapter is to determine theoretical guidelines for restructuring the ESI in order to enable it to achieve the objectives of public policy. The sections below will each include a brief overview of the key concepts, illustrative local and international experience and the relevant debates. In conclusion, guidelines are proposed that will act as the basis for detailed policy proposals.

\subsection{Governance}

The overall relationship between government and utilities can be characterised as one of 'governance', which can be understood as the 'cluster of control relationships between public authorities and utilities' (McGowan 1991: 5). Electricity utilities in all countries, whether publicly or privately owned, are subject to significant public governance, because (a) electricity systems are considered to be a strategic element in a country's economic infrastructure; and (b) transmission and distribution networks are viewed as natural monopolies. ${ }^{1}$ Governance can take various forms: direct control through government oumership, more formal control through regulation, and the general control exercised through legislation pertaining to areas such as safety, environmental protection, investment, macroeconomic management and monopoly control (anti-trust legislation). Governance expresses the notion that, as part of the national political process, governments determine the forms of ownership and the specific forms of control over the ESI on the basis of their social and economic policies and ideological leanings. Government controls the ESI primarily in two ways. As the executive of the state, it controls publicly-owned enterprises in terms of property rights; and if it enjoys the support of the legislature, it controls the ESI (private or public) through legislation. Governments often choose to relinquish ownership of the ESI while maintaining legislative control and formalising the regulatory mechanism. The ownership and regulation of enterprises are thus always part of the wider governance equation, and must be evaluated in this context.

The present organisation of the ESI, in terms of governance and structure, is largely the result of the nature of historic government control over the industry. Chapter Two illustrates the case of South Africa in this respect.

\subsubsection{Energy policy, supervision and utility management}

\section{The separation of energy policy formulation and utility management}

1. Generation is not, strictly speaking, a natural monopoly, but the large capital requirements and lengthy investment commitments in practice prohibit all but the largest players

from entry. trol governance of state-owned industries, where national energy/economic policy formulation is conflated with enterprise management. The function of energy-sector policy formulation is largely a political process that demands a careful balancing of interests and wider economic concerns. It requires very different skills from those needed for the day-to-day management of a utility. When these functions are not 
separated, for example, when a utility is run as a government department under direct political control, confusion of roles occurs. Management becomes caught up in political processes that encourage behaviour contrary to that required for efficient business management, while politicians, often motivated by short term political considerations, can make poor management decisions.

When the roles of policy formulation and management are institutionally separated, it becomes easier for managers to focus on running an effective and financially viable enterprise. This institutional separation promotes the utility's ability to fulfil the important role it has to play in policy formulation on the basis of the economic imperatives of the enterprise. The separation of energy policy formulation from utility management requires that utility governance be concerned with ensuring the efficient implementation of public policy, rather than day-to-day control. This leads to a preference for an 'arm's-length' relationship between government and utilities, formalised transparent control, independent regulation and often the appointment of governing councils (World Bank 1993a).

\section{The role of stakeholder control}

The principle of stakeholder participation, has been established in Eskom's Electricity Council and in forums such as the National Electrification Forum (NELF). Any analysis of governance in South Africa has to include a review of the potential role of stakeholders.

Power to effect control over the ESI is demanded by many stakeholders, whether they are represented on a governing board or not. These players include government, owners, management, labour, suppliers, consumers, (other) groups from civil society and often, lending agencies. The demand for 'accountability' is, to a large extent, a demand for some form of stakeholder control. A review of ESI stakeholders would be incomplete without highlighting their interests in exercising a level of control over the industry.

- Governments demand control over the ESI in order to implement public policy. Countries that allocate significant powers and functions to sub-national government have to decide which tier of government will control electricity supply.

- Owners, whether public or private, demand control in terms of property rights. Their control is often mediated by a regulator, indirectly representing the interests of other stakeholders. In practice, the state as owner could cede most of its control to an appointed regulator or governing board. Private owners will not often voluntarily cede control.

- Management control the day-to-day operational decisions in the organisation within the governance framework. They usually wish to increase the size of the system under their control, and thus have an propensity to influence investment decisions.

- Labour, as a central factor of production, demands control, often through its role in wage and service condition negotiations. They also have an interest in influencing the overall policy for the ESI in as far as it effects growth in the industry and in the broader economy.

- The suppliers of fuel, goods and services have an incentive to control ESI decisions, especially those that affect investment plans.

- Consumers demand control over the services delivered to them. Although they also have influence through national government as voters, through private capital or cooperatives as shareholders, and through trade unions as members, consumers also demand direct control as central stakeholders. Other groups from civil society, such as environmental protection groups, also demand a say in utility decisions. 
- Multilateral and other lending agencies demand control to ensure the 'successful' implementation of the funded projects, and the repayment of the loans they have made.

Assuming that lending agencies, management and suppliers have a less rights in playing a role in governance than other stakeholders, the roles of key stakeholders are evaluated as follows below.

In democratic countries, consumers (the most important group of stakeholders) are indirectly represented by a government which is elected by them. The advantage of this route of representation is that sectoral interests have, in theory, been politically balanced and mediated by other national governing concerns. It is on this basis that a democratic government can take a dominant role in controlling the industry. Although they should not replace the legitimate political process, direct consumer representatives in the ESI governing process could, on the other hand, mediate policy emanating from government which is probably political partybased, on the basis of their expertise in the service demands and interests of the specific consumer sectors that they represent.

Industrial and commercial organisations, which are not necessarily represented by the government, being central players in a market economy, have an important role in this context. In South Africa, strong pressure will exist to cross-subsidise small, mostly new domestic consumers with revenue generated from industrial, commercial and established domestic consumers. Stakeholders could have common or conflicting interests, and it is thus important that all interests are represented in the governance process. A comparison of Eskom's tariffs with those of a wide range of local authority tariffs is revealing with regard to their respective governance processes. Eskom's tariffs are generally more cost-reflective than those of municipalities, who tend to overcharge their industrial and commercial consumers. The stakeholder representation in Eskom's Electricity Council, which includes a wide range of industrial, commercial, mining and established domestic consumers (i.e. white municipalities), largely explains its more balanced tariffs. Local authority councils are, the other hand, represent only domestic consumers (the voters), which explains their lower domestic tariffs and higher industrial and commercial tariffs.

Stakeholders should thus have a direct role to play in electricity policy formulation, but there are a number of problems associated with the way in which a stakeholder board (such as the Eskom Electricity Council) operates. Members are often passive rather than pro active. They tend merely to react to management submissions (as opposed to pro actively introducing new ideas) and then only when they perceive their interest to be directly affected by the proposals. Furthermore, they generally do not have the capacity to undertake their own long-term planning. In this context, the management board effectively has carte blanche (Morgan 1993b). More significantly, stakeholder board members are generally not specialists in the electricity industry, and are (in the absence of a professional independent regulator) probably easily influenced by the management of the utility. Lastly, a stakeholder board that is representative of strongly opposed interests, might not be a very effective decision-making body, and could become immobilised by deadlocks or, at best, make 'compromise decisions' that are based on trade-offs, and which merely reflect the balance of power on the board. Stakeholders thus cannot always adequately supervise a utility and may require additional support; a role that could be performed by a regulator (to be discussed later).

On balance, it can be concluded that in addition to government, stakeholders (i.e. consumers and labour) have a limited, but important and direct role to play in pursuing their interests in electricity policy formulation and in utility supervision. 


\subsubsection{Ownership}

Public policy on the most appropriate ownership of the ESI has seen dramatic changes over the last century. South African governmental policies have closely mirrored international developments. After allowing early private initiatives to provide the mines with electricity in South Africa, the state intervened in 1922 by creating the Electricity Supply Commission (Escom). The aim was to coordinate and extend the supply of electricity as an important infrastructural service, in order to facilitate industrial development (Merz \& McLellan 1920). The effective monopolisation (and nationalisation) by Escom of most the generation industry after 1948 reflected similar developments elsewhere in the world. ${ }^{1}$ Towards the end of the 1980s, much emphasis was placed on privatisation and the introduction of competition into the ESI in industrialised countries such as the UK, Europe and the USA, and in developing countries such as Argentina, Chile, Thailand and China. Again, South Africa followed suit, and the privatisation of Eskom was set as the government's first target in its privatisation programme (State President's opening speech in parliament 1988, quoted in Horwitz 1993: $44-45$ ). The initiative was sidelined as a result of strong opposition from Eskom's consumers and the powerful South African trade unions (Clare 1989; CRIC 1989).

ESI privatisation involves a process of transferring the ownership of public enterprises into private hands, and is usually combined with the introduction of competition, often through appropriate regulatory changes. Proponents of privatisation assume that competition and private profit motives will necessarily lead to an improvement in ESI efficiency. However, efficiency improvements can also be encouraged within different public utility models. Also, improving cooperation within the industry might reap larger benefits than attempting to foster competition, especially in developing countries (Teplitz-Sembitzky 1990). These issues are discussed below.

\section{Improved efficiency}

For the proponents of privatisation, a central concern is to avoid the inefficiencies in investment planning, construction and operation, which have occurred in the past in public utilities in industrialised and newly industrialising countries, but especially in developing countries. Tenenbaum et al (1992: 1134) argues that the underlying reason for these inefficiencies is that 'when the state owns, nobody owns; and when nobody owns, nobody cares". It is generally argued by proponents of privatisation that managers of privately-owned enterprises, in contrast to their publicly employed counterparts, operate within an incentive structure that links their remuneration and career prospects to their ability to ensure an adequate return on the capital invested in the enterprise. They will therefore (barring monopoly powers in large markets) be much more effective in improving planning, construction and operational efficiencies. Improving the effectiveness of management incentives is thus an important motivation for privatisation.

Recent research in the UK power market has indicated that although the competitive privatisation of the power sector resulted in lower costs for power companies, these costs were not passed on to consumers in the form of lower tariffs. On the contrary, profits have soared and tariffs were found to be between 20 per cent and 25 per cent higher than they would have been under public ownership (MacKerron 1993). This has resulted in a large shift of economic surplus from consumers to shareholders (MacKerron 1994).

Hasson (1992: 6) also reports that after privatisation and the introduction of competition in the bulk market during 1991/92 bulk electricity prices were significantly higher in Argentina. Although it is still too early to draw final conclusions, preliminary results seem to indicate that while privatisation can lead to an increase in micro-efficiency in the operation of utilities, this does not necessarily mean that these benefits are passed on to consumers in the form of lower prices or improved
1. Similar developments took place in, inter alia, Argentina (Hasson et al 1992), the UK and France (McGowan \& Thomas 1992) after World War II. 
service.

The problem with the incentives under which managers of privately owned enterprises act, is that they are primarily aimed at maximising the return on investment over the short- to medium-term, rather than at the sustainable provision of an essential public service.

Private capital perceives an increased risk when evaluating the return on total assets, and making future investment decisions in a competitive environment with increased uncertainties; it also requires a higher rate of return than a monopolistic public sector utility. Risk averseness leads to a preference for shorter project cycles and lower sunk investments (even if this results in higher fuel costs). This ultimately results in decisions being taken that are very different from what would have been the case if the optimal allocation of national energy resources was the major priority, rather than obtaining a high rate of return. The prudent exploitation of natural energy resources, such as a large hydro-electrical potential (for example, in Brazil and Argentina), or vast low-grade coal deposits (for example, in South Africa) ${ }^{1}$, often requires significant in vestments that will only be recovered over long periods. Such in vestments are generally unattractive to private investors a situation that is presently giving rise to concern in China, Argentina and Chile, where present patterns of private investment result in lower fuel and capital efficiencies, and a sub-optimal allocation of national energy resources (Wirtshafter \& Shih 1990; Hasson et al 1992).

The privatisation of energy investment planning and a reliance on 'market mechanisms' only could exclude non-monetised considerations such as environmental externalities and security of supply, and could also potentially result in a deterioration of efficiency in the national economy over the medium- to long-term (Fells \& Lucas 1992: 387).

The debate about private or public ownership of the ESI relates to the roles that utilities can play as public service organisations or as commencial enterprises. Publicly-owned utilities operate under a service motive, while privately-owned utilities are motivated by the pursuit of profit. The essential question is whether an enterprise, motivated by the desire for profit, will deliver a sustainable service more efficiently and cheaply than a service-orientated public enterprise.

If the issue is really one of effective management incentives (or motives), as argued above, it would not be the correct approach to be fixated on a single option for incentive improvement, i.e. privatisation. Recent World Bank policy literature is rightly concerned with the contradictory and ineffective management incentives and the lack of management accountability that is often found in publicly owned enterprises. They correctly conclude that this is essentially a problem of governance and ineffective regulation. But the World Bank (1993a) then goes on to suggest privatisation as a solution (thereby potentially introducing a host of new problems), instead of also exploring ways in which present practices of public governance could be revised and adapted to promote effective utility management.

Yarrow (1989) states that in situations where significant market failures prevail (for example, monopoly conditions and environmental externalities), it is not ownership that matters, but regulation. De Oliveira (1991: 88) argues that the 'dichotomy between privatization and state control is a mistaken one. Developing countries should rather look for a rational balance between public and private ownership, but most importantly under a new regulatory regime' [my emphasis]. Experience with public sector utilities in recent years clearly shows that 'when the state owns', it could easily result in a situation where 'nobody cares', but the many examples of gains made by public utilities since World War II in Latin America (for example, Argentina, Brazil, Chile, Mexico), Europe (for example, UK and France) and South Africa, illustrate that public ownership provides an opportunity for rational inte-

1. Advanced technology employed in Eskom power stations enables the burning of coal with a low calorific value, thus freeing coal resources of higher quality to be utilised for other purposes, or to be exported. 
grated resource planning that could have outcomes superior to those that might result from private sector power planning.

\section{Competition or cooperation: The need for coordination}

In their attempt to establish the necessary coordination to obtain an efficient and effective application of resources in the ESI over time (for example, in investment planning, generation dispatch, operation and maintenance), decision-makers are faced with two choices: simply put these are whether to place emphasis on a process of rational planning and cooperation, or whether to rely on a motive of maximising the return on capital in an environment where prices are determined by competitive market pressures, to determine priorities. The former option is an approximate description of the case where the supply is undertaken by a public or private utility that has been granted monopoly status. The latter option is illustrated by the case of the UK's ESI, where privatisation was combined with the introduction of competition. The argument that privatisation results in improved efficiency is, to a large extent, based on the assumption that effective competition can be introduced into the ESI.

However, many have questioned whether effective competition is possible within the ESI. For example, Prime Minister Jan Smuts in 1937, at the opening of Escom House in Johannesburg, argued that electricity for South African industry was

as cheap as anywhere in the world because wasteful competition had been eliminated.... There will always be a very large field for private capital to operate in, but there are certain industries which experience has taught us can be driven better by the Government without loss through wasteful competition. (Quoted in Horwitz 1993: 5).

At that time it was generally accepted that the ESI was most efficiently operated as a monopoly, whether it was privately owned and tightly regulated, or publicly owned. Coordination and planning activities were based on cooperation rather than competition.

The development of interlinked transmission grids and modern pricing theory contributed to renewed debate in the 1980s, which questioned the view that the ESI is a natural monopoly. The desirability of monopoly supply and the possibility of introducing competition have been re-examined. There has been a movement towards 'deregulation' in the USA, Australia and Europe, and full privatisation and competition in England and Wales ${ }^{1}$ and New Zealand. It is now widely accepted in most industrialised countries (with the notable exception of France) that competition in generation is possible and desirable even if it has not yet fully been attained and that competition by suppliers for the provision of an unbundled service ${ }^{2}$ to end-consumers could even be instituted.

In South Africa, Eskom's large over-capacity in generation exemplifies the potential planning weaknesses of a public monopoly, and limits the present possibilities of introducing generation competition. However, Eskom power stations are presently operated as virtually self-contained units with separate cost centres and accounts, and limited benchmark competition is practised.

The large electrification backlog in South Africa, high capital costs and the highly politicised demand for affordable electricity (low tariffs) makes it inconceivable that private distributors would compete to supply electricity to poor township residents.

Cooperation or competition do not necessarily imply either public or private ownership, although competition often requires a degree of private ownership. It is conceivable that the considerable self-generation capacity of large municipalities and industry, and the possibility of industry turning to other energy sources, has acted as an effective competitive pressure on Eskom, and has contributed to the

1. Under the current circumstances, whereby the two largest generating companies control over $60 \%$ of available capacity, the level of real competition in the UK generation business is questionable and, increasingly, the regulator has to guard against monopoly powers. It seems that this is largely a result of the hasty way that the industry was privatised, and does not reflect conclusively on the outcome of a carefully planned privatisation and 'deregulation' programme.

2. Generally, the distribution of electricity to end-consumers takes the form of a bundled service, weheby the energy and distribution (transport) is provided as one service. In an attempt to extend supply-competition to end-users these services can be unbundled, so that consumers could choose a different energy supplier from that supplting to its distribution utility. Consumers in England and Wales with a supply of more than $1 \mathrm{MW}$ are currently entitles to choose their bulk supplier. Current plans are aimed at allowing all households to choose their own bulk supplier by 1998 . 
maintenance of low prices and an acceptable quality of supply (Horwitz 1993: 53). The threat of alternative bulk supply options available to large consumers could work to contribute to the efficient management of Eskom and low tariffs in the future.

Competition can occur in many different ways ranging from competitive bidding for ancillary services to competition in core services such as power generation. Competition for the provision of ancillary services is largely uncontroversial. It is the introduction of competition to the core business of the ESI, as discussed above, that is subject to controversy (World Bank 1993b: 3).

\section{Access to finance}

The need to finance capital-intensive power sector growth has played a definitive role in determining ESI ownership structures over the last century. Internationally, increased public involvement in the power sector after World War II enabled continued ESI expansion to facilitate industrial development. The debt crisis and recessionary budget constraints that evolved in the developing countries during the 1980s have resulted in a shortage of capital for continued power sector investment. Whereas financing constraints led to the nationalisation of the power industry in many countries during the 1940s, they now contribute significantly to the drive for privatisation of the ESI, as a means of enabling further growth in the industry. The increased uncertainty brought about by privatisation, deregulation and competition increases the lender's risk exposure, and has significantly increased the cost of capital. Higher capital cost will dramatically affect electricity prices in developing economies.

Where utilities are too close to government and political interference has resulted in unrealistically low tariffs which threaten financial viability, utilities are unable to raise affordable finance for investment. However, a large public sector utility, operating at arm's-length from government in a stable policy environment that reduces uncertainty and lender's risk, is potentially at a distinct advantage concerning its ability to raise finance. Eskom provides a good example of the financial success that may be attained by effectively governed and managed public utilities. Eskom is consistently able to raise finance at lower interest rates than the South African government, and has significant foreign participation in its rand bonds. ${ }^{1}$

Indications are that low-cost finance for electrification and capacity expansion will be readily available to large, public sector utilities that are not facing significant uncertainties about the future structure of the sector, and which are able to minimise the lenders' risk and ensure long-term financial viability by meeting their revenue requirement through over-all cost-reflective tariffs.

\section{Corporatisation and commercialisation}

Utilities can be effectively situated at arms-length from government by establishing them as public corporations. This will achieve a clearer separation between the governing and management functions of the utility, and it will be possible to improve the utility's efficiency by commercialising its operation and management.

1. In terms of nominal value, $52 \%$ of Eskom Rand stock was held by foreign investors by the
Corporatisation essentially entails the transfer of assets from a government ministry to a separate publicly-owned corporation. An organisation is thus consolidated and given an independent existence enabling it, to a large extent, to set its own employment and financial policies, and to enter capital markets independently. The total separation of government and utility bureaucracies is intended to increase productivity as a result of improved performance management, clearer accountability and greater exposure to market forces. Corporatisation is an effective way of establishing an arms-length relationship between government and a publicly owned industry. It could also be the first step towards (but does not necessarily lead to) privatisation. 
An interesting example of a public corporation model that experienced significant problems is to be found in the ESI in England and Wales before privatisation. The industry was effectively an monopoly supplier and consisted of the Central Electricity Generating Board (CEGB), twelve area boards which retailed electricity, and the Electricity Council which acted as the overseer and coordinator of the whole industry (Rodriguez 1987). The industry operated as a public corporation within a statutory framework set out in Acts of Parliament, as well as non-statutory controls determined by central government. Although the ESI was supposed to operate at arms-length from government, it experienced increasingly closer government control. These were mainly financial controls and were initially intended to increase the industry's efficiency; however by the 1980 s, government control was motivated more by political objectives, such as the pursuit of monetarist policies (Surrey 1986). The government intended to reduce the public sector borrowing requirement by limiting treasury loans, and by increasing revenue from the nationalised industries, through means such as requiring them to repay capital debts faster than planned (Surrey 1986: 43). This level of government interference in the ESI occurred because, in contrast to the relative financial independence of the public corporation model espoused above, the ESI was required to use the Treasury to meet its borrowing requirements, which subjected it to a high level of government influence over its management. To avoid this kind of problem, public corporations should be set up to operate with a high level of financial independence, and free access to financial markets. Corporations should also not be expected to make transfer payments to government for reasons other than to pay back loans with clearly contracted repayment schedules.

In South Africa, a public corporation can be established in a number of ways. A public undertaking can typically be incorporated in terms of a special act, as is the case with the Eskom Act (No. 40 of 1987) which established Eskom; or the corporation could be established in terms of existing legislation, such as South Africa's Companies Act (No. 61 of 1973). In this case, the shares could be owned by a government department and limited equity participation by private investors could also be a possibility. A number of difficulties, however, are associated with the issuing of shares as part of a corporatisation process:

- It will prove difficult, if not impossible, to determine the value of the undertaking's assets.

- The undertaking will remain a monopoly and the existence of shareholders alone will not necessarily guarantee more efficient management or cheaper electricity.

- If a stakeholder model of governance is favoured, the issuing of shares to parties other than the stakeholders, or even to stakeholders in a different proportion to their voting rights on the stakeholder governing body (for example, if all the shares are owned by a government department), could lead to a situation where shareholders demand a say in the utility affairs in proportion to their share ownership. In such a case, a conflict of interest could develop between the shareholders, and the stakeholders and the stakeholder governance system could be undermined.

A process of corporatisation is usually combined with commercialisation, with the aim of improving management efficiency. Commercialisation means that business conduct is based on commercial principles. Organisations are treated like commercial enterprises: they have to earn a market-related return on equity, conform to commercial accounting standards, be exposed to 'market discipline"; often the payment of taxes and dividends is also involved. Corporatisation and commercialisation provide a way of reforming public utilities with the aim of exposing the organisation to discipline enforced by the market, while retaining the advantages of public ownership. 
With the exception that Eskom does not pay taxes or dividends, and has no shares, it has to a large degree been corporatised and commercialised in terms of, inter alia, sections 3, 4, 12, 20 and 22 of the Eskom Act (No. 40 of 1987).

\subsubsection{Regulation}

Governance (the relationship between the state and the ESI) is affected by ownership and stakeholder involvement (discussed above), but it also, crucially, involves regulation. In this paper, regulation does not refer to all forms of government control over the industry; and neither does it refer to the political process of energy policy formulation. ESI regulation usually involves at least some degree of public price control, but normally extends to control over other areas of utility conduct, such as levels of service, and planning and investment decisions. In a competitive environment, however, the regulator's focus is more likely to be on defining and enforcing the rules of the game. Cordukes (1990) defines regulation rather narrowly as 'the enforcement and monitoring of a set of operational rules to meet defined objectives by an appointed autonomous agency accountable to government". The World Bank (1993a: 9) refers to regulation within the specific context of private or arm's-length public enterprises. For the purposes of this paper, regulation will refer to professional control exercised over public arm's-length, or private industry by an autonomous public agency, with the aim of defining operational rules and providing independent review and intervention in order to meet the objectives of public policy.

In countries with corporatised public utilities, an additional (often dominant) form of public control often exists in the form of a board of stakeholder directors appointed by government. ${ }^{1}$ Although stakeholder control is often loosely referred to as regulation, this paper treats it as a related but distinct function.

\section{Theories of regulation}

Regulation may be better understood by referring to the following theories, reviewed by Horwitz (1989: 22-45), largely in the context of private investor-owned utilities in the USA. Although the theories are highly simplified in the summaries presented here, they nevertheless illustrate the value of a critical analysis of the governance system.

\section{'Public interest' theory}

Public interest theories explain the genesis of regulatory agencies as a response to the perceived conflict between private corporations and the general public. The establishment of regulation is seen as a democratic victory for 'the people' over private corporate interests, through the exercising of the powers of the democratic state. Progressive public interest theory is based on a rather naive faith in the administrative ability of a regulating bureaucracy to protect the voiceless consumers and to ensure rationality and fairness in the economy.

\section{Regulatory failure theory}

According to Horwitz 'Regulatory failure theorists are public interest theorists betrayed' (1989: 27). These theorists assume the public interest as the raison d'être and theoretical standard for regulators and then proceed to examine the practice of regulation, often finding that the public interest has been subverted by regulators who serve the interests of the in dustries being regulated. Generally this is explained as the result of over-identification of the regulator with the industry that is being regulated. This is largely argued by influence models, which suggest that regulated industries inevitably come to have undue influence over the regulators.

1. Both EdF in France and Eskom have a stakeholder 'board of directors'.

\section{Conspiracy theory}

Conspiracy theorists share the same opinion of the results of regulation as adherents of regulatory failure theory. It is in their understanding of the origin of 
regulation that they differ from the two previous theories. Theirs is the radical argument that regulatory agencies are set up in order to serve the interest of private industries. Conspiracy theorists also criticise the establishment of protected (private) monopolies with 'public utility status', ${ }^{1}$ alleging that this constitutes a victory for capital in coopting the modern state (Gray in Horwitz 1989: 32).

\section{Organisational theory \\ 'Organisational theory' refers to a group of studies of regulatory policy that attempts to explain regulatory behaviour in terms of organisational theories. One variant holds that regulators will be preoccupied with organisational preservation and the employment of regulator personnel, thus being regulation-oriented rather than industry-oriented. They will thus attempt to solve all problems in the industry by doing what regulators do: making more and improved regulations. Another variant of the theory holds that regulators will tend to avoid conflict and attempt to make compromises with all the parties involved, thereby forming consensus networks that reflect the effective balance of power, rather than acting as an critical input to the governance of the electricity industry.}

\section{The capitalist state theory}

The capitalist state theory is based on a theory of the state as structurally dependent on the private accumulation of capital, through corporate taxation. Private industry, destabilised by the anarchy of the market, calls on the state and its extensions to regulate the market in order to ensure rationality and the management of externalities. The apparent paradox of an 'independent' state acting in the interest of capital is explained by the state's structural dependence on the private accumulation of capital.

A comprehensive theory of regulation would have to analyse both the genesis and practice of the regulator, as well as its interest in self-preservation as an organisation. It would also have to account for the democratic state functioning under the dual constraints of having to facilitate the private accumulation of capital by securing economic growth and performance on the one hand, and on the other, having to pursue legitimation by meeting democratic demands for equity and due process (Horwitz 1989: 43-4). It would also have to incorporate an understanding of the behaviour of organisations that are being regulated, and would have to suggest ways of understanding the behaviour and motivation of managers. In this regard, for example, there is an important difference between regulating private and public enterprises. Explained rather crudely, managers of investor-owned enterprises have an incentive to maximise profits by virtue of their private ownership. Managers of publicly-owned enterprises, left to their own devices, could face a very weak or contradictory incentive structure and thus be left with few performance imperatives. In both cases, regulation has an important, albeit different, role to play. Given the preference expressed for arm's-length public ownership, the rest of this section is aimed at analysing governance processes based on this model.

\section{The role of regulation under different ownership regimes}

It is important to identify how the role of regulation changes under different ownership regimes a distinction that is often neglected in theSouth African debate. It would make no sense, for example, to uncritically transplant the experience of regulated investor-owned utilities in the USA to the South African context, where the ESI would probably be publicly owned.

In the case of privateenterprise, as has been noted above, managers tend to be given stronger incentives to generate financial profits, rather than to provide a public service. Where they have been granted monopoly status (as in the USA), tariffs have generally been subjected to rate-of-return regulation. Regulation is being extended more generally to utility conduct as a result of concern about the environment, and the effect that private investment decisions can have over the long term on costs. ${ }^{2}$
1. In the USA, private companies providing an essential public service under monopoly conditions (such as electricity) are given 'public utility' status, whereby they are placed under the regulatory authority of the state Public Utility Commission.

2. In a competetive bulk market, private generation investors, preferring shorter project cycles, could make investment choices in terms of technology and fuel combinations that result in higher costs and taritfs. 
Insofar as competition has been introduced to an industry that is largely privately owned (as in the UK), regulators are primarily concerned with maintaining competition (or, more often, attaining real competition) and establishing the rules of the game. Prices are left to be determined by demand and supply in the market.

Practically all publicly owned utilities operate under monopolistic conditions and, as noted above, could face very weak, or contradictory, incentive structures. The most important consideration for any regulator, in this context, is that managers be given specific incentives to improve performance. Gains in operational and investment efficiency would generally only be achieved by the establishment of a strong incentive framework with effective performance indicators. The regulator would have to supervise and audit the whole spectrum of performance outcomes. However, it would be much easier to install a public service ethic and obtain management cooperation in the case of public ownership, as there is no 'alternative' agenda to maximise profits. In a context of strong and effective governance, the role of a regulator would be crucial, given the limited role that stakeholders play in practice. With this large and rather technical task at hand, the regulator would require strong technical skills, and should constitute a centre of technical expertise outside the utility.

In a developing country with a government under pressure to deliver affordable social services, a regulator might also have the role of protecting the ESI from undue government interference in day-to-day operational decisions.

The respective roles of a regulator and stakeholder board under public ownership The respective roles assigned to a regulator and stakeholders (including government) are determined by the trade-off between 'technocratic rationality (expertise)' versus 'inter-subjective consensus (politics)' as modes of public decision-making (Horwitz 1992: 40). Electricité de France argue that the introduction of an independent technocratic regulator 'may be a good idea', but that alone it is insufficient (World Bank 1993b: 59). They argue that there is a de facto 'regulatory body' that involves stakeholders such as government ministries and labour (similar to the stakeholders discussed under 'The role of stakeholder control' above) and point to the importance of involving stakeholders:

This de facto body may hold contradictory views, but these relate to real problems and most of them should be considered.

The real challenge is designing institutions and procedures for coordinating these different views, so as to make efficient decisions. Taken alone, the Anglo-Saxon concept of the independent [technocratic] agency does not answer the question. Indeed, it may even make it more complex, depending on the country and its institutions.

Although the role of a technocratic agency is not precluded, EdF considers the incorporation of a plurality of stakeholders as fundamentally important. Given the large role reserved for stakeholders, a regulator's role is to do what stakeholders are weakest at: the proactive supervision of utility management and investment planning on the basis of technocratic rationality. Its responsibility should thus essentially be to inform, mediate and audit the governing processes on the basis of its technical expertise.

The role established for stakeholders, on the other hand, should enable them to do what they do best: look after their own interests. They should do this by participating in the formulation of electricity policy and by co-supervising the implementation of public electricity policy by the utilities.

\section{Modes of regulation}

For the purpose of this paper, three generic modes of formal regulation are identified: rate-of-return regulation, price-cap regulation and incentive regulation. 
Rate-of-retum regulation

Under rate-of-return (ROR) regulation, profits are regulated by determining tariffs on a cost-plus basis, with the aim of assuring the investor an adequate return on the capital invested. The most important criticism of ROR regulation is that it provides little incentive to improve efficiency and cut costs, but rather allows for increased costs to be passed on to consumers, despite regulatory lag and the risk to utilities that costs will be disallowed by the regulator. ${ }^{1}$ It could also provide utilities with an incentive to inflate the asset base that is used to calculate the required rate of return, leading to over-investment or 'gold plating' (Horwitz 1992).

Most investor-owned (private) utilities in the USA operate under ROR regulation imposed by the state Public Utilities Commissions. ROR regulation requires that accurate information on the operation of the utility be available. The amount of work required to implement the system can be considerable. The Public Utility Commissions in the USA typically employ between 120 and 650 personnel, mostly professional staff (Morgan 1993a: 53).

\section{Incentive regulation}

Incentive regulation refers to a group of regulatory approaches that attempt to implement a hands-off approach to regulation by specifying clearly measurable performance goals, and by linking incentives to their achievement. Instead of focusing the regulators' efforts on the application of resources as in the case of ROR regulation, incentive regulation concerns itself with the outcome of the utility's actions. A well known example of incentive regulation is found in Britain, where the regional electricity companies in England and Wales are price-cap regulated with the commonly used formula RPI $-X+Y$. The retail price index (RPI, a measure of inflation) is taken as the basis for price increases, and is then adjusted by a small percentage (the ' $X$ ' factor) which the company must make up in increased efficiency, plus or minus an allowance for any other factors (' $Y$ '), such as a provision for any exceptional investment requirements (McGowan \& Thomas 1992: 157). The price-cap mechanism, despite its price focus and apparent simplicity, risks the same shortcomings as ROR regulation (McGowan 1991: 7). The system provides for a cost-of-service review every five years with the aim of determining a price which becomes the new base for the RPI-X formula; however, as Tenenbaum et al (1992: 1145) point out, it does have the advantage of a built-in regulatory lag of five years (in other words, the cost-of-service review, which is similar to a ROR cost allowance, is only undertaken every five years).

It could be argued that a fundamental difference between ROR regulation and price-cap regulation is that under ROR regulation, the regulator has to police costs and not quality, and under price-cap regulation, it has to police quality and not costs (Tenenbaum et al 1992: 1158 footnote). As pointed out above, an utility under ROR regulation does not have such a strong incentive to cut costs, and could even be tempted to inflate its asset base. It would thus be unlikely to skimp on quality of supply, the costs of which it can legitimately pass on to consumers. Under price-cap regulation, on the other hand, utilities cannot easily pass costs on to consumers, and would thus have a stronger incentive to implement cost-cutting measures, some of which might compromise the quality of their electricity service (Besant-Jones 1992: 148).

\section{Performance contracting}

Whereas ROR and price-cap regulation are normally applied in industrialised countries with largely privatised ESIs, performance contracting is increasingly being applied in countries with publicly-owned ESIs. Performance contracting is an attempt to give utilities more autonomy within the framework of a performance agreement. Utilities are held accountable for desired outcomes, as measured by a negotiated set of performance in dicators covering a wider scope than simply return on investment or electricity price. The principles of performance contracting are
1. Tenenbaum et al (1992: 1144) argue that, although the regulatory lag between when a cost is incurred and when it is allowed by the regulator, and the risk that an investment $\theta x-$ pense might be disallowed, act as weak incentives to cut custs, ROR has few incentives to improve efficiency. 
also used in affirmage and concession arrangements. ${ }^{1}$

In countries with publicly owned utilities that are both government-operated and governed, performance contracting positions utilities at arm's-length from government. Governments thus limit their interference in utility affairs to a minimum, enabling greater managerial and financial autonomy for the utility. Government still determines overall policy, sets objectives and coordinates sector development planning. Government also remains responsible for establishing the legal framework to protect the interests of various stakeholders (World Bank 1993a).

The most common form of performance contracting is through the establishment of a contract plan (CP), as is the case with the national electricity utilities in France, Morocco, Guinea-Bissau, Senegal and Ivory Coast (Cordukes 1990: 16). Eskom's pricing compact, although narrowly defined, also bears some resemblance to a contract plan. ${ }^{2}$

A contract plan is a negotiated agreement between government as the owner of an enterprise, and the management of a utility. It contains details of the intentions, obligation and responsibilities of the two parties over a specific time period typically three to five years. The resources available to the utility and the constraints acting on it will be detailed. Financial and physical performance measures will be agreed upon, usually covering areas such as productivity targets, price levels, sales and investment strategies, and self-financing and debt strategies (World Bank 1993a). The frequency and process of the evaluation will be detailed and the appropriate reward and remedial measures agreed to. CPs will typically give managers more freedom in most aspects of management, including remuneration policies, in return for the required level of performance. Ultimately, senior managers are held personally accountable for performance. Contract plans detail the obligations of both utilities and government. Government also has an obligation to ensure an appropriate environment within which the utility will be enabled to fulfil its task. At the annual performance evaluation, the performance of both parties must be evaluated.

1. Affirmage: an arrangement between a govemment and a foreign firm for the management of a public utility. Concession: a contract under which a public authority assigns a private party the task of supplying a public service.

2. In this compact covering the period from 1992 to 1996 , Eskom undertakes to (1) reduce the price of electricity by $20 \%$ over five years; (2) increase productivity by $20 \%$ over five years; (3) improve its debt equity ratio; (4) maintain quality of service at international standards; (5) further the aim of electrification without subsidising from other consumer classes; (6) use excess capacity to sell electricity to industrialists as prices above short-run marginal costs; (7) base price adjustments on Eskom's revenue requirement; and renegotiate the compact if economic indicators should move outside a specified economic framework.
The advantages of performance contracting spring from the fact that all the different pressures acting on a utility can be channelled into one negotiating 'forum', which will ensure that performance objectives are able to be set according to the full equation of considerations. Not only will this result in more realistic performance targets being set, but it will present management with a coherent task and associated accountability.

With regards to price setting under performance contracting, Electricité de France argues that 'regulations should not move sharply away from cost-plus towards fixed-price arrangements' (World Bank 1993b: 59). The concern is that under strict fixed-price (price-cap) regulation, the utility's financial risk might be increased, which in turn would lead to an increase in cost of capital. It is thus proposed that strong incentive mechanisms, such as price-capping, be limited to operating and maintenance costs.

\section{Besant-Jones argues that:}

To be consistent with the objective of commercializing state-owned utilities, and in particular accountability, a performance contract should be made between the government represented by an administrative ministry and the Board of Directors of a utility, rather than directly with the utility managers. Government should leave to the directors the task of motivating managers and staff to meet performance targets. (1992: 150)

It would depend on the nature of the board of directors whether it would be best for the board or management to be the contracting party. If the board consists mostly of industrialists and others, appointed for their experience and expertise, it 
would make sense for the board to be the contracting party. On the other hand, if, for example, regionally based distribution utilities have stakeholder boards, as is the case with the Eskom Electricity Council, it would probably be more practical to make management the contracting party. Stakeholder board members will generally be less skilled at the task at hand, and could be divided among themselves, making it difficult to negotiate a sensible contract plan. Giving management, acting under board supervision, a more prominent role under such circumstances will probably result in improved contract plans.

The success of performance contracting is limited by the information on which the initial plan is developed, and the performance evaluation is based. Effective management information systems, including budgeting, accounting and reporting systems, will be important throughout the performance management process (Cordukes 1990: 42). Poor quality of information flowing from the utility could result from the failure of management information systems due to limited capacity in the utility, management bias, or deliberate manipulation. A regulator could play an important role by providing independent reviews and audits of information used in the CP negotiation process.

Besant-Jones (1992: 149) argues that government should not be the judge of its own performance, but that an independent body should perform such an evaluation. The need for independent utility and government performance audits, and the need for abody to deal with contingencies in between planning periods, all point towards the importance of the role of an independent regulator to support a CP based governance system.

\section{Structure of the regulator}

There are some important factors that should guide the establishment of a regulatory authority.

A strong case is to be made for situating the regulatory authority in one central body responsible for the whole industry. In the case of both Argentina (Hasson et al 1992: 17-18) and the USA (Tenenbaum et al 1992: 1136), problems have been reported when regulatory functions (governance in the case of Argentina) are split between the federal and state levels. As electricity systems become increasingly interconnected, the reliability of supply, effectiveness, and allocative and productive efficiency depend more heavily on the successful functioning and coordination of the system as a whole. When, under split governance, subsets of an integrated system operate under contradictory governing paradigms, problems with performance will result. The effective autonomy of local government distributors in South Africa, and the ineffectual national regulator (the Electricity Control Board) are the most important causes of the problems currently experienced in the industry.

In developing countries, the scarcity of skilled personnel is a further reason for establishing a single regulator, and raises the question of whether the regulator should not also control other industries, such as telecommunications and transport. Given that the role of a regulator is conceived of within a very specific governing paradigm, it is assumed that unless an industry occupies a position in the economy similar to that of electricity, and has similar ownership, it would probably not be practical to place it under the same regulator. 


\subsection{Structure}

The structure of the ESI essentially refers to the way in which the basic functions in the industry are grouped and institutionalised. This section is aimed at identifying broad principles or performance guidelines for a future ESI structure.

\subsubsection{Deferminants of the ESI structure}

The development of the ESI structure and changes therein are generally determined by the interaction of a multitude of (often interdependent) factors. Some of these determinants are unrelated to the ESI in their origin, while others arise from within the industry. These factors can also be detrimental, neutral or advantageous to the performance of the ESI. Some of the most important determinants are discussed below.

\section{Changes in the governing paradigm}

Three factors in the governing paradigm can affect the ESI structure, namely, changes in social and economic policy; changes in the preferred ESI ownership; and national constitutional changes.

A significant change in the orientation of government social and economic policy could result in structural changes in the industry. The active pursuit of industrialisation by the governments of the UK, Argentina and South Africa after World War II, for example, resulted in the nationalisation and restructuring of the ESI in those counties. Similarly, it is the move away from apartheid policies, together with a greater emphasis on the equitable provision of social services, that has precipitated the present move to restructure the South African ESI.

More specifically, a change in the preferred ownership paradigm could result in structural change in the industry. The choice of public ownership as a result of the nationalisation programmes of the 1940 s referred to above, generally resulted in the amalgamation of separate companies into a public monopoly. Similarly, the privatisation programmes of recent years often resulted in the break-up of public sector generation monopolies, as in the case of the Central Electricity Generating Board in the UK and in New Zealand. ${ }^{1}$

The constitutional development of a country could effectively dictate the structural development of the ESI. It is inconceivable that a public monopoly such as Electricite de France could have developed in a federal country such as the USA. The allocation of powers and functions to sub-national government in South Africa's future constitution could effectively foreclose on certain structural options for the ESI. Strong regional government, for instance, would probably disqualify the possibility of establishing one national distributor and, at the same time, would establish regions as 'natural' boundaries for distributors.

\section{The need to exploit economies of scope}

The development of technologically specialised base-load, intermediate- and peakload power stations, together with the construction of high-voltage transmission

1. A programme by the Argentine govemment during $1966-80$, aimed at decentralising and commercialising generation, ironically resulted in the government controlling more than $99 \%$ of the generation capacity by 1980 , as a result of the failure of private enterprise in the difficult economic circumstances in the energy sector at the time (Hasson et al: 15-16). lines that enable the interconnection of networks and power stations, increase the potential to exploit economies of scope. This has implications for the structure of the ESI. If investment planning and operations control are coordinated on a national basis, it is possible to minimise the national surplus capacity in terms of base-, intermediate- and peak-load stations while, at the same time, coordinating the operation of the system to minimise fuel costs. It thus makes sense to centrally coordinate generation and transmission investment planning and system operations.

The need to exploit economies of scale

The quest to optimise economies of scale is also dependent on the available set of 
technology. In coal-based generation, for example, the development of coal-fired generation technology has led to the construction of larger generating units. Other developments in transport, information processing and communications technology also affect the optimal structure of the ESI.

It has not been conclusively shown that economies of scale exist in the distribution of electricity. An 'un written norm' of a minimum of 10000 consumers per undertaker is acknowledged by the DMEA (1992: 21). The DMEA (1992) also cite van der Merwe's report of an in verse correlation between the size of distributors (measured in terms of annual electricity sales), and the average price per unit of electricity sold in South Africa. As the DMEA points out, the reduction in electricity price can be explained by increased economies of scale and an improved demand profile. Unfortunately, it is not clear what proportion of the observed price decrease is related to a flatter demand profile, and therefore lower bulk-purchase price. Penn (1992: 5), on the other hand, maintains that no fundamental economies of scale exist in the distribution of electricity, but that those support services that do exhibit economies of scale can be provided by joint programmes between distributors.

Clearly there are many areas of the distribution business, such as human resources management, training, financial management, planning (standardisation etc), marketing, bulk-purchasing, spares holdings and network control that will demonstrate economies of scale. The logical approach will be to have large distributors that will allow the decentralisation of those functions which show no economies of scale and which benefit from decentralised specificity, while simultaneously enabling the centralisation of those functions that do show economies of scale.

\section{The need for functional differentiation}

In industrialised and newly-industrialised countries over the last decade, there has been a trend towards the organisational separation of generation and distribution. This was largely motivated by the difference in the nature of the two activities. The distribution sector has developed to become a commercially based, service-oriented activity, involving constant interaction with consumers who demand satisfactory 'customer service". The generation sector, on the other hand, has been characterised by escalating capital and fuel costs, and increasing public demand for environmental protection. This has led to greater sophistication in the technological base of construction, operation and maintenance, demanding a continually specialising work force. Developments in the nature of these activities have thus followed divergent paths; their separation has become necessary to ensure that a 'focus on the core business' could be retained.

The separation of distribution from generation and transmission will free the distribution management from senior generation and transmission management, which dominates in vertically integrated monopolies. It will also expose distribution management more effectively to consumer demands. Management will thus tend to adopt a more independent approach, and be obliged to act in the consumer's interest when negotiating with generation and transmission.

More recently, there has also been a move towards separating transmission. The formation of national transmission grids requires central coordination of operations (dispatch). Attempts to establish generation competition (at the margin, or in the whole industry) and international electricity trade, require that the dispatching authority be independent from the generators. In South Africa, the most important initial change will be to separate distribution from generation and transmission in order to allow distributors to focus on customer service, electricity end-use and electrification. The separation of transmission itself will become an issue only when South Africa's excess generating capacity is exhausted. 
The need to minimise the cost of finance

The availability of low-cost finance is affected by industry structure as well as by the governing regime. Enterprises faced with a large demand for electrification would have to borrow heavily to finance an electrification programme. With regard to structure, those with a large revenue-generating asset base, and a healthy balance sheet, would hold a distinct advantage over smaller distributors in minimising the lender's risk, and thus facilitating easier access to low-cost finance.

\section{The locality and nature of the consumer base}

The locality of consumers and their movement (for example urbanisation) could potentially affect the distribution function. A change in the number of poor domestic consumers as opposed to wealthier domestic, commercial and industrial consumers, which will be a result of the electrification process in South Africa, could have an effect on the desired ESI structure. If the geographical spread of high- and low-consumption consumers within a region is very uneven, it would make sense to have larger distributors to enable the sustainable delivery of electricity to all consumers, by maintaining realistic average revenues and costs.

\subsection{General conclusions and guidelines}

The following guidelines, determined in this chapter, will be the basis for a detailed policy proposal in Chapter Four.

\section{GOVERNANCE:}

Policy:

- Electricity policy formulation and utility management should be institutionally separated.

- In addition to indirect participation in policy formulation through democratic government, stakeholders should have a direct role in electricity policy formulation and utility supervision.

Ounership:

- The ESI should remain predominantly in public ownership.

- Stable public-sector governance ensuring long-term financial viability will facilitate access to low-cost finance.

- While remaining in public ownership, utilities should operate as arm's-length commercial corporations.

\section{Regulation:}

- Utilities should be supervised through incentive-based contract plans.

- There should be a national, professional regulatory body with powers over the entire ESI.

- The regulator should act pro-actively to inform, mediate and audit the governing processes on the basis of its technical expertise, and effective information systems.

\section{STRUCTURE:}

- The changing political and constitutional context in South Africa requires the restructuring of the ESI.

- Generation and transmission investment planning and system operations should be coordinated centrally.

- Distribution should be separated from generation and transmission.

- Distribution should be consolidated into a small number of large distributors. 


\section{Policy proposals}

\subsection{Introduction}

A future government will give high priority to the provision of social infrastructure such as housing, water, sewerage, roads and electricity. In the case of electricity, as with many other services, it has become clear that the delivery system is tightly bound up with the fragmented local government inherited from apartheid. Accelerated short-term delivery will thus depend on the extent to which present systems can be adapted and redirected, while medium-term policy must attempt to fundamentally restructure delivery systems. Policy making will increasingly have to differentiate between short-term management of the transition, and medium-term restructuring goals.

Medium-term goals are here defined as goals which reflect the proposed structure for the industry as it should exist in three years' time. Medium-term and short-term transitional issues are closely related. Decisions about medium-term policy goals give overall direction to short-term policy, while short-term solutions set precedents that could affect, and even foreclose, medium-term options.

Medium-term policy options that fall within the policy guidelines determined in the previous chapter are evaluated in this chapter, and the final proposals are discussed in some detail. Proposals for the structure of the industry are distinguished from those for the governance of the ESI. The short-term management of the transition is discussed in the final chapter.

Medium-term proposals are partly based on assumptions about the development of economic, social and political factors external to the ESI. Because the accuracy of such assumptions is necessarily limited, medium-term policy proposals constitute development goals rather than an attempt to prescribe the precise condition of the industry over three years. As time goes by, knowledge about the future economic, social and political environment will improve, and should result in an ongoing review of longer-term, development policies.

\subsection{Structure proposals}

In accordance with the guiding principles determined in the previous chapter, it is proposed that the functions of generation, transmission and distribution should be separated. Given the challenges of a major national electrification programme over the next twenty years, it is proposed that distribution should be institutionally separated from generation and transmission.

\subsubsection{Distribution}

Given that distribution should be institutionally separated from generation and transmission, two central questions have to be answered: how will the distributor borders be determined (in the case of more than one distributor); and who will be responsible for specialised distribution functions, such as rural electrification (RE), or the electricity needs of very large consumers, that require special distribution capabilities.

\section{Distributor borders}

The following determinants of the ESI structure identified in the previous chapter should have a direct bearing on the determination of distributor borders: 
- The powers and functions (including electricity) delegated to sub-national government.

- The need to capture economies of scale and scope.

The location of present and future consumers.

The powers and functions of sub-national government as determined by Chapter 10 of the Constitution of the Republic of South Africa Bill (B 212-93 (GA)) and the Local Government Transition Bill (B 214-93 (GA)), provide for concurrent powers over the supply of electricity. Local government powers are subject to national legislation. The above determinants thus all favour rationalisation of the currently fragmented distribution industry by establishing a few (less than ten), large distributors. The different options for establishing rationalised distributors are identified as follows:

a) Future provinces could be adopted as the boundaries for distributors.

b) Distributor borders could be drawn on the basis of technical considerations such as the location of consumers and bulk supply points, and the financial viability of the new entities. These functional regions would probably not coincide with constitutional provinces. The Association of Municipal Electricity Undertakings (AMEU) has put forward a proposal for six functional regions. The supply side database compiled by the National Electrification Forum could be used to model the proposed distributor models in terms of the potential consumer base, human resource requirements, financial flows and the asset base.

c) All distributors could be amalgamated into a single national undertaking.

In all of the above options, distributors will have internal divisions for decentralising geographically-bound management functions, but they will also be able to benefit from the economies of scale that can exist in the distribution of electricity.

Establishing electricity distributors along future provincial borders would implicitly situate the distributors within the political tension between provincial and national government. Both tiers of government could be tempted to obtain an unhealthy level of direct control over distributors in an attempt to gain an upper hand in the national versus provincial power struggle. Such structuring would constrain the effectiveness of the governance system outlined below. Both the other suggested structure options would sit comfortably with the suggested system of governance.

\section{Rural electrification}

The larger resource requirements of rural electrification (RE), its net financial drain on supply authorities (Van Horen 1994), and the important role it could play in rural development, all require careful consideration when the responsibility for $R E$ is assigned. Foley (1992: 283) points out that rural electrification is often in conflict with the primary concerns of utilities mandated to implement it. This conflict relates to the low returns derived from rural electrification, and the temptation to divert resources to other, more financially rewarding activities. Foley also points to the low prestige afforded rural electrification by the implementing organisations, and the resulting difficulty in attracting the attention of competent staff. He suggests that the problem could be solved by creating a separate rural electrification agency, either in the form of an internal division, or as an organisation external to the existing utility.

In addition, three important issues have to be considered.

a) It must be ensured that the required resources for electrification, system operation and network maintenance are available to the distributor involved, 
and that the rural lobby has adequate leverage when resources (largely finance) are allocated.

The issues of lobbying for resources and distributor accountability are often raised in the context of the structure of delivery organisations, but they are, strictly speaking, related to the governance of the industry. In terms of governance, it would be rational to separate the formulation of rural electrification policy (and thus decisions about the allocation of resources), from the day-today management of the distributor. The issue of lobbying for rural resources could be addressed most effectively at the level where national energy and electricity policy are determined; in other words, at the level of national government itself (specifically in the Energy Policy Council, discussed under the medium term governance proposals below). Here it would be possible for the rural lobbies to combine resources and act in unison when demanding rural service delivery.

b) Rural electricity will have to be delivered efficiently with the minimum of overhead costs to enable the service to be extended as far as possible.

It would be counterproductive to have a duplication of infrastructure in one geographical area. Separate rural distributors would have severe resource constraints, even with potential national subsidisation, while distributors that service metropolitan areas only could potentially generate large surpluses. The problem could be solved by having larger distributors servicing a combination of urban and rural areas.

c) Distributors responsible for rural service will have to closely coordinate electricity supply with other development activities and community requirements, in order to ensure that the benefits of electrification are maximised. Community participation in electrification planning, and contribution to the costs of electricity supply, could be enabled by the establishment of cooperatives that contribute to construction, electricity vending, maintenance and fault reporting.

The rural lobby should thus be given representation at the level where national electricity policy is formulated and guidelines about public resource allocation (such as grant funding for rural electrification) are determined. Rural electrification will be most effectively undertaken by large regional distributors or a national distributor with an internal division responsible for rural electrification. Resource allocation should be both formalised and transparent, and the rural electrification division should have access to external grant funding. Clear objectives should be set against which performance can be appraised. The rural electrification division should develop specialised methodologies for rural electricity supply that should involve supporting community participation and ground-level institutional development.

\section{The national electrification fund}

A national electrification fund could be established to facilitate electrification during the transition of the ESI and thereafter (Van Horen 1994). It could have two main functions:

a) to raise loan and grant finance for electrification; and

b) to allocate this finance equitably between households over time.

Initially this fund could be financed by a fiscal grant, which should be used as seed finance to raise further loan and grant funds. Foreign donors could also contribute to the initial seed finance. In theory this could also receive support in the form of a levy on electricity sales. However, such a levy could only be imposed after wide negotiation. When future grant funds for electrification become available, the 
benefits could be spread equitably by channelling them through the electrification fund, where they could be used as collateral to raise further finance.

The fund may fall under the control of the Energy Policy Council (proposed below), but its administration could be contracted out to the Development Bank of southern Africa, or Eskom. Funds should be allocated on the basis of priority rules determined by the Energy Policy Council.

\subsubsection{Generation and transmission}

Although generation and transmission lie outside the main focus of this research, some broad pointers to areas that require further investigation are appropriate.

In terms of Section 16 of the Electricity Act (No. 41 of 1987), Eskom has effective control over the acquisition of any new generation plant in South Africa and does not, in practice, allow other parties to acquire large generation capacity. However, the possibility of providing grid access to independent generators and co-generators in the future, should be investigated. Although the economic rationality of these options might sound questionable given Eskom's current surplus generating capacity, there are important reasons why they deserve further investigation:

- The real cost of transmitting power to regions that are far from the Eskom generation centre of gravity in the Eastern Transvaal, is higher than Eskom's current two to three per cent transmission surcharge. Rough estimates indicate that the line losses from the Transvaal to the Western Cape alone run to more than 3 per cent. The capital, maintenance and operating costs of the long-distance transmission networks have to be added to the line losses to calculate the real transmission differential. If the real transmission cost of electricity is taken into account, electricity generated closer to the source of consumption, in areas far from the Eastern Transvaal, could be competitive, despite the potentially higher generation costs.

- National demand growth has a very close correlation to GDP growth; if South Africa's economy begins to expand again, electricity demand will grow in kind, and new generating capacity will be needed.

- The thousands of poor households that will be connected to the national grid over the next fifteen years as part of the accelerated national electrification programme, will significantly increase national peak demand. Although the problem could be addressed by demand side management measures up to a certain extent, household electrification will rapidly absorb the spare generating capacity on the national grid.

- Increased co-generation could increase energy efficiency and energy conservation.

- Plans to build an interconnected southern African grid will be slow in implementation, and will not meet the growth in South Africa's electricity demand by the turn of the century.

- The threat of municipal competition has possibly played a role in stimulating Eskom's generating efficiency in the past (Horwitz 1993). Limited marginal competition could constitute an effective incentive for efficiency improvements in future.

- The involvement of foreign capital in the construction of new power stations could constitute an important additional source of capital for South Africa.

If alternative generation sources, as discussed above, become desirable from a national energy policy perspective, transmission could be separated from generation to ensure impartial grid access and dispatch. Eskom's current divisional separation between Generation and Transmission should thus also be maintained. 
The final decision on the ownership and continued operation of the few municipal coal-fired power stations (about four per cent of national capacity) should be based on economic considerations. Assuming that future distributors retain these power stations, it is proposed that they be charged the same cost-reflective bulk tariffs (for example, time-of-use) as others, and that they should not be given any financial incentives not to use these power stations, as is currently the case with the special Eskom discounts. As long as Eskom acts as the supplier of last resort, and has to ensure that it can supply any demand, distributors should pay Eskom an availability charge for an amount equivalent to the capacity of their power stations should they wish Eskom to act as a backup supplier. If Eskom similarly requires the availability of distributors' power stations for security of supply reasons, distributors should either receive capacity discounts from Eskom, or they should be remunerated for the service.

Faced with cost-reflective tariffs, distributors would make rational decisions about the continued operation of old municipal power stations. In the long-term, most would probably be closed down.

\subsection{Governance proposals}

\subsubsection{Ownership}

Chapter Three concluded that electricity must be supplied as a public service by public corporations that are at arm's-length from government. Although there are many ways of institutionalising public corporations, the Eskom model of a statutory public corporation with no share-holding has set a precedent for establishing arm's-length governance of public utilities in South Africa. Electricity distributors could be established in the same way, by means of a new electricity act that specifies the rights and obligations of distributors and defines the relationship between bulk suppliers (generators), distributors, consumers, the regulator and government.

\subsubsection{Options for the governance framework}

In Chapter Three, a broad framework of guidelines was created, which outlined the respective roles of government, stakeholders, the regulator and utilities in the governance process, on the basis of separating policy formulation from utility management. In this section, two models for the governance framework are developed which fall within the governance guidelines. These models were also chosen to resemble a likely outcome of the ESI restructuring negotiations as they are played out between the National Electrification Forum, local government representatives and national government. A third preferred governance model is developed and evaluated in the following section.

The discussion of the financing options available for a national electrification programme, in Chapter Two, concludes that cross-subsidies from the existing national consumer base would probably be an important part of the financing strategy. Together with the governance guidelines, the viability of cross-subsidies thus also need to be taken into account when evaluating the following models.

There is little controversy over the policy role of government and stakeholders on a national level. A proposal for a national stakeholder Energy Policy Council is developed in the next section, and is an essential component of the governance equation in the models discussed below. The need to provide a role for a national regulator and stakeholders in utility supervision, as pointed out in Chapter Three, is also acknowledged in the development of these models.

\section{Provincial Electricity Councils}

It is feasible that, for political reasons, electricity could end up becoming a provincial function after the current restructuring of the South African state. This would 
be the result of strong regional political interests, and it can be expected that provincial government will demand to play in important role in the governance of the ESI. From the point of view of the ESI and its consumers on a national basis, this would be an undesirable situation, as argued earlier in this chapter. A national governance model could be developed to deal with this situation, as indicated in Figure 4.1.

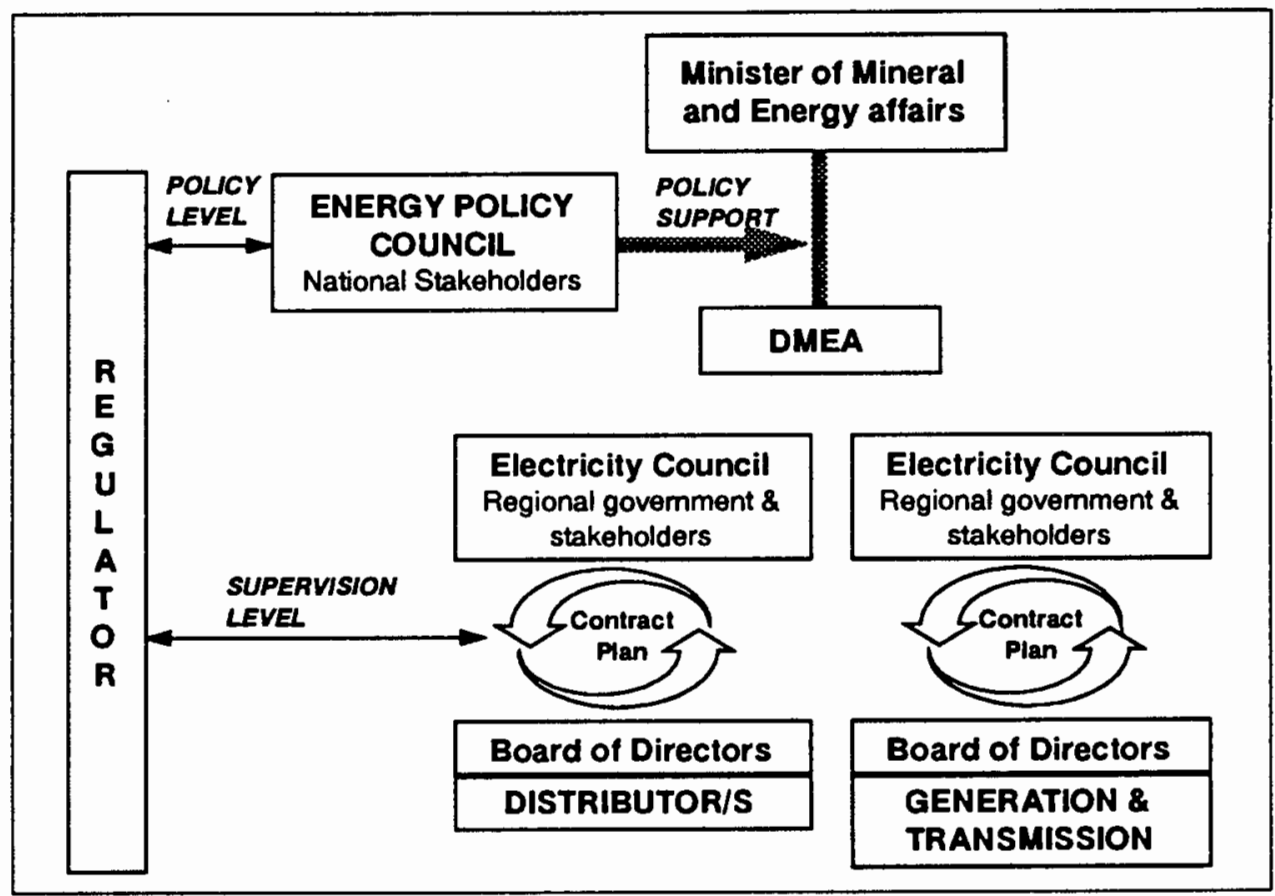

FIGURE 4.1 The governance framework for provincial distributors

According to this model, policy for the ESI is formulated by national government and a national Energy Policy Council. Policy guidelines are promulgated by the minister of Mineral and Energy affairs. Provincial distributors are supervised by a provincial Electricity Council, which incorporates representatives from both local and provincial government and stakeholder groups. The supervisory relationship is formalised through the establishment of a contract plan that enables an arm's length relationship to be maintained between the distributor and its Electricity Council. The contract plan is also a public document which will promote transparent utility governance. The national electricity regulator ensures the implementation of national policy guidelines in the provincial contract plans through the power it has to invalidate a contract plan if the latter is in conflict with national policy.

A governance model of this kind has the advantage of providing stakeholders at a provincial level with significant influence over the industry operating in their province. However, this high level of provincial control is also potentially the cause of most of the problems related to this model. There are to be nine provinces in post-election South Africa, and preliminary studies indicate that if distributors are arranged along these borders, they would differ dramatically in size, and most of them would battle to implement the electrification programmes that would be required of them. Large financial transfers between distributors would be required, which could place a significant burden on the national regulator if it was expected to supervise these transfers. This problem could be partly resolved by discarding the idea of financial transfers between utilities, and rather implementing a national levy, in favour of the proposed national electrification fund, on bulk electricity sold to distributors.

A further problem with this model is that national union and civic organisations might experience difficulty in finding skilled representatives for all nine provincial 
electricity councils. In the absence of strong household consumer and labour representation, the electricity councils would be dominated by large commencial consumers and provincial and local government.

\section{Regional Electricity Councils}

The electricity distribution industry can be rationalised, along functional lines, into four to five large distribution utilities with their own stakeholder electricity councils. A governance framework similar to that of the provincial model above can be implemented. This model would experience the same problems discussed above, but to a lesser extent. However, the contract planning process between the utility and the electricity council would now be complicated by the involvement of at least two provincial governments, and a wide range of stakeholders. The provincial governments would represent different constituencies, who could possibly have conflicting interests. It would be difficult for the electricity council to present the utility with a coherent set of proposals for a contract plan.

\subsubsection{National Energy Policy Council}

The preferred model for industry governance is presented in the remaining part of this chapter. This model is developed both for a single national distributor, or a few (about five) large regional distributors. A broad outline of the proposal is provided in Figure 4.2, and is then briefly described. The institutional roles and the governance processes are discussed in more detail in the sections that follow.

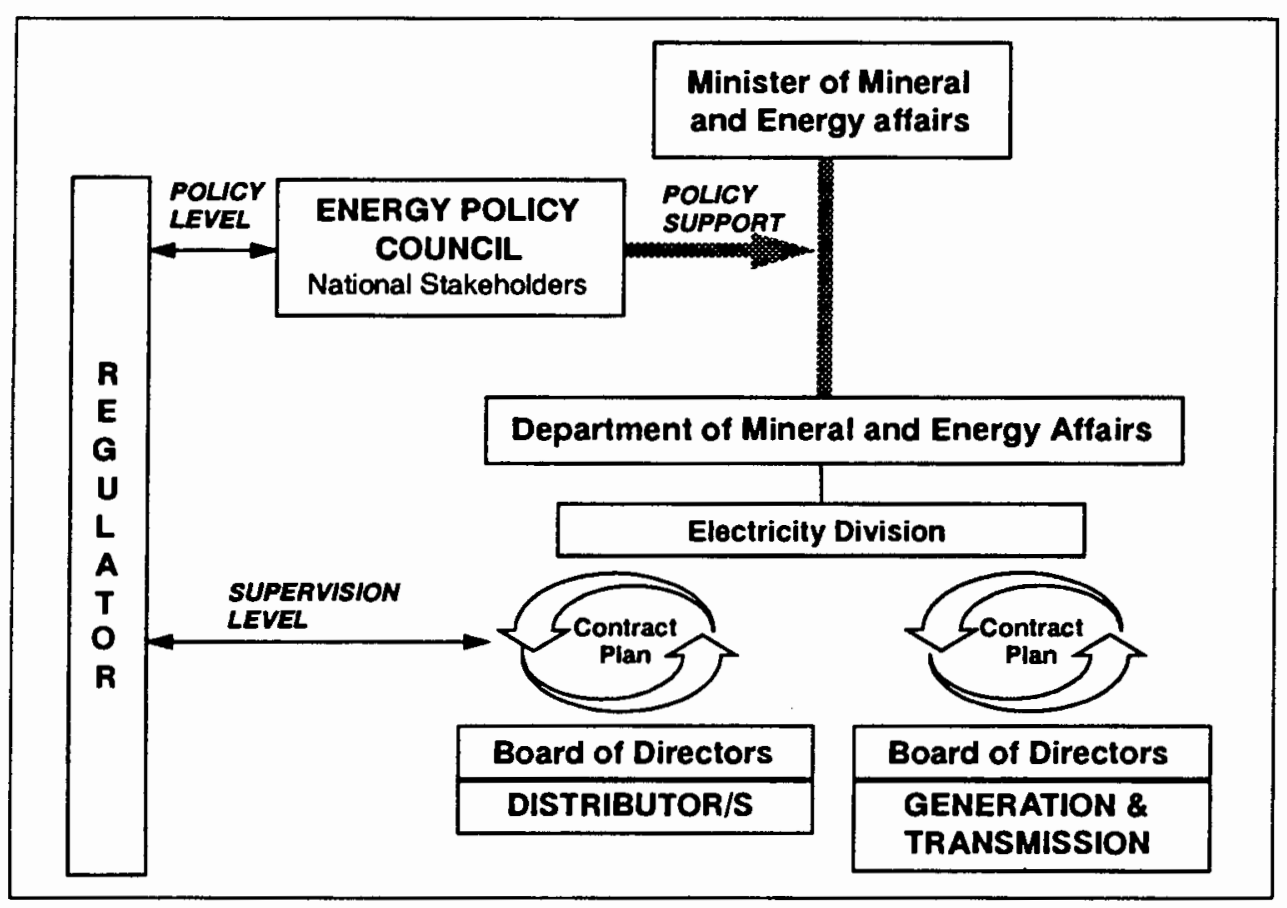

FIGURE 4.2 The proposed electricity governance framework

According to the proposal depicted in Figure 4.2, governance takes place at two levels, namely, energy policy formulation, and utility supervision. National government appoints a stakeholder Energy Policy Council (EPC) in terms of an energy act. The council advises the minister on energy policy, and is responsible for macro-planning to support policy formulation. It reflects these objectives by being structured on two levels. The policy level includes representatives from the departments of Finance, Mineral and Energy Affairs (DMEA), Development, and others if necessary. It also includes provincial government as well as representatives of key consumer groups and labour. The general planning level is staffed with professionals who are responsible for all the planning and research activities 
required to support the development and implementation of policy. The EPC will constitute the core of the national energy policy formulation process, and will give a high profile to central stakeholders in the energy economy. All governmental energy policy processes should also be obliged to involve the EPC.

The central policy implementation relationship (utility supervision) is embodied in a negotiated contract-plan (CP) agreement between the DMEA, as the administrative representative of government, and the utility board of (mostly executive) directors. The agreement includes a broad range of negotiated performance targets in terms of service and financial parameters. Contract plans are three to five year agreements, but are reviewed annually. The chief executive director is appointed in terms of the agreement. Other executives are appointed by the chief executive, and their appointment is confirmed by the DMEA. Service conditions and re-appointment are based on performance in terms of the $\mathrm{CP}$ agreement.

A national electricity regulator is the custodian of the CP process, and is empowered to act as a referee to ensure unprejudiced $\mathrm{CP}$ negotiations.

\subsubsection{The instifutional roles}

This section explains the role of the different players in more detail.

\section{National govermment and the Energy Policy Council}

National government plays a central role in the governance process. The minister of Mineral and Energy Affairs appoints the Energy Policy Council to enable stakeholder participation in the policy formulation process. The stakeholder representation is detailed in an Energy Act, and the minister appoints the representatives from short lists presented by the stakeholder bodies. The EPC is thus a body that will emerge from the National Electrification Forum (NELF) and the Eskom Electricity Council. It will take over the policy functions of the Eskom Electricity Council and local government councils (with regard to present municipal distributors).

Energy and electricity policy is formulated through an interactive process between the respective government representatives and other stakeholders in the EPC. A methodology of integrated energy planning should be adopted, which takes longterm views of all the energy-service needs of consumers, and all the primary energy sources available to the economy. The EPC should take technical advice from the regulator and utilities. Electricity policy determined at this level should be aimed at providing investment-planning, financing, tariff structure and tariff level guidelines that will form the basis of the utility contract plans.

The minister implements fundamental aspects of electricity policy by promulgating regulations that will be binding on utility conduct in terms of a new Electricity Act.

The role of the DMEA is essentially to administer the implementation of relevant legislation and public policy. The utility contract plans should thus be negotiated by the DMEA in terms of the electricity policy developed in the EPC. An internal Electricity Division represents government and stakeholders in the contract planning process. It could draw on the macro-planning function in the EPC, and the technical skills and financial knowledge of the regulator to inform it during the $C P$ negotiations and reviews (to be discussed below). The DMEA Electricity Division thus takes over the supervisory function of the Eskom Council and local government councils.

\section{Provincial government}

Provincial governments will play a central role in ensuring service delivery in their areas of jurisdiction. In the case of electricity, the need for provincial control is coordinated with the need for national control by situating provincial government representatives in key positions in the national governing process. Provincial representatives are thus included as key stakeholders in the Energy Policy Council. 
They could also be included in the Electricity Division of the DMEA when it negotiates with the distributor supplying its province. At least one provincial representative should be included in the negotiations with the national generation and transmission utility (currently Eskom). Provincial government should not have direct legislative control over electricity supply.

\section{Local government}

At present, local government's interest in retaining electricity is based not so much on ensuring the delivery of an essential infrastructural service, as on the independent revenue base that electricity often provides. Access to large electricity surpluses reduces local government's dependence on national or provincial fiscal transfers, and effectively gives them greater autonomy.

The corporatisation of electricity distribution implies that electricity supply should be removed from local government control, leaving those that were dependent on electricity surpluses with a reduced revenue base. The current restructuring of local government should be accompanied by a restructuring of the state fiscal transfers in order to ensure an adequate local government revenue base. Broad agreement on the restructuring of local government finances will be crucial to the corporatisation of electricity distribution.

\section{Utilities}

The daily affairs of the utility are to be conducted by a board of executive directors. The chief executive can choose to appoint non-executive directors, such as experienced industrialists, financiers or key stakeholders, to advise the board (Dingley 1993). Director remuneration and reappointment are linked to the utility performance measured in terms of the contract plan. The board negotiates the contract plan, and reports on the utility's performance in terms of the performance indicators agreed to in the performance contract. They also play an important role in:

- investment planning;

- the determination of tariff levels;

- developing supply options; and

- determining appropriate service levels.

\section{The regulator}

The regulator constitutes an centre of technical and financial expertise to that acts as an alternative to that provided by the utilities. It provides a source of independent expert information a function that is not present in government (including the Energy Policy Council), or anywhere outside of the utilities. On the basis of its expertise, it will:

- facilitate and mediate the contract planning process;

- review and comment on DMEA and utility submissions to the CP process;

- audit utility submissions during CP negotiations and reviews;

- approve decisions on reserved contingent issues inbetween $\mathrm{CP}$ review periods (discussed below);

- act as an ombudsman in the case of a deadlock in CP negotiations or in utility-consumer negotiations; and

- support the EPC in integrated energy planning and policy formulation.

As part of its review function during the $\mathrm{CP}$ negotiations, and its role as consultant to the EPC, it will also have a specific brief to:

- partake in investment planning;

- partake in tariff design;

- translate government/EPC electricity policy into a contract plan framework; and

- determine formulae, on the basis of EPC guidelines, for surplus transfers (if necessary). 
The regulator is established in terms of a statute, possibly a revised Electricity Act, and is independent from government. To ensure its operational independence, it is funded by a small levy on electricity sales, approved by parliament. Its budget adheres to a framework of rules as set out in the Act, and its books are audited annually by the auditor general. The regulator is managed by a board of professionals, who are appointed by parliament from a list prepared by the EPC. They are to be appointed on the basis of their expert knowledge of the ESI. A large staff (more than 50) will enable the regulator to fulfil its duties.

\subsubsection{The contract plan}

The contract plan (CP) forms the heart of the utility governance process. The contract plan records a negotiated agreement between the DMEA and the utility board of directors. It specifies the rights and obligations of both parties (government/EPC and the utility board of directors) over a period of up to five years. The agreement contains the central components of a five-year business plan for the utility, by specifying a set of strategic plans and performance indicators. It defines how the performance indicators will be measured, and sets performance targets in terms of the indicators. Performance indicators should reflect a comprehensive set of technological, environmental, social, macro-economic and micro-economic goals, as stated in the national energy policy statements. Annual performance targets are not set on an ad hoc basis; they are part of a longer term business plan.

The board is provided with incentives linked to the performance targets specified in the agreement. The CP identifies circumstances (such as dramatic changes in inflation or the GDP growth rate) under which a party would be allowed to request a re-negotiation of five-year performance targets.

\subsubsection{The negotiating process}

The drafting of the contract plan is an iterative process. In broad outline it could develop as follows: the regulator presents the DMEA with a standard contract plan skeleton that contains the essential elements for a successful CP, and which reflects national energy policy and electricity regulations. The DMEA Electricity Division develops the framework to reflect their requirements within the manoeuvring space available, and they then present this to the utility. The utility proceeds to develop a five-year business plan aimed at meeting the criteria of the proposed CP. On the basis of the business plan, the utility alters the CP and presents it to the regulator for review, before presentation to the DMEA. The detail of the $\mathrm{CP}$ is then negotiated to the point where both the parties (DMEA and utility) agree on realistic outputs within the resource constraints. During the CP negotiating process, the regulator should provide an independent review of the implications of the respective proposals.

The negotiated planning process is illustrated by the example of generation and transmission investment planning. In this case, investment planning is the responsibility of the dispatch authority (the utility responsible for transmission control), the regulator and the EPC. The EPC determines the broad policy outlines and presents them to the DMEA. The dispatch authority undertakes the long-term planning, and investment plans are submitted to the regulator, who provides an independent review of the proposals, and is empowered to return the plans to the utility for further investigation if it is not satisfied. Resubmitted proposals have to be passed on to the DMEA, but the regulator is entitled to comment in an independent report attached to the proposal. The final agreement is made between the utility and the DMEA.

Electrification planning is in the first instance undertaken by the distributors who participate in local electricity planning committees. These committees are set up to provide local government and local stakeholders with an mechanism for influencing utility activities in their area. Distributors also cooperate with the national 
electrification planning database, situated in the EPC, that enables global electrification targets to be set. Global targets are in turn also used by the utilities to develop detailed business plans, which are translated into performance indicators as part of the respective contract plans. During contract planning, the details of the electrification plans are negotiated in the same way as generation and transmission investment planning.

Once a CP is agreed on the utility is left to manage its affairs for the rest of the year. The question arises as to how, during the year, the utility should deal with contingent issues that would normally form a significant part of contract plan negotiations, but which require quick decisions. The regulator can be empowered in terms of the electricity act to have a veto power over any such reserved decisions. The CP should also specify what issues are reserved for regulator approval. These issues should only include decisions that can have a long-term affect on utility performance and the cost of electricity. Reserved issues should never transgress the principle of arm's-length governance, and the regulator should be empowered to disqualify any stipulations that it deems to be in conflict with arm's-length governance.

The contract plan is reviewed annually. The annual review process comprises three steps:

a) utility performance is reviewed;

b) the planning horizon is extended for another year, based on the past year's performance and developments in the external economic and social environment; and

c) the contract plan is subsequently adjusted on the basis of the review process, where necessary.

Submissions presented by the utility during the annual review process are to be scrutinised and commented on by the regulator before they can be tabled at the review meeting between the DMEA and the utility board. The regulator has the right to audit these submissions before it confirms their factual accuracy. A backstop mechanism is built in to deal with a possible deadlock during the CP negotiation and review process. The electricity act specifies the conditions under which a matter would be referred to the regulator for arbitration. Recourse to the courts is possible on procedural grounds.

The regulator is generally not empowered to dictate agreements between government and the utilities. But it does have the power to intervene and order utility or DMEA submissions to be returned for further development or revisions before allowing them to be presented for negotiations under the following circumstances:

- submissions do not adhere to the national electricity regulations as promulgated by the minister;

- submissions do not adhere to the aims of national energy policy as specified by a national energy strategy (to be determined by the EPC);

- the regulator deems submissions to be contravening specific stipulations of the electricity act (for example, when, in the absence of other sources of revenue, overall tariff levels do not enable the revenue requirement to be met);

- the regulator finds submissions to be factually incomplete or incorrect (especially during performance reviews).

The governance process is further illustrated by the following points. 


\section{Tariffs}

Tariffs are determined by a two-stage process. Guidelines for tariff structures are determined by the Energy Policy Council, as a central part of electricity policy. The tariff level, on the other hand, is a central part of the CP negotiations, and is determined independently of the tariff structure.

It would be possible for the EPC to specify a national range for domestic tariffs if it wishes to standardise domestic tariffs. The regulator would in this case determine the minimum and maximum levels involved.

\section{Surplus transfers}

Given the uneven geographic distribution of present and future consumers, it will probably be necessary to transfer operating surpluses between distributors (in the case of multiple distributors). The regulator would then have to determine how surpluses should be transferred from one distributor to another. There are many ways of affecting the transfers, but some important guidelines would have to be applied.

- In the context of a governance process based on a contract plan, it is important that, by determining the revenue transfers, the regulator does not present the utility with a set of incentives which are not part of the $C P$. If revenue transfers are based on indicators that are not included in the $\mathrm{CP}$, the utility could be faced with contradictory incentives, which might result in inefficient management. The method of determining the revenue transfer should thus be based on performance indicators that are negotiated as part of the contract plan, such as target sales and operating costs.

- The revenue transfer process will impose strong incentives on distributors, and it is necessary to ensure that these will have the desired effects. Transfers should always present incentives that motivate utilities to minimise costs and improve their service in terms of quality and access. They should thus not be solely based on cost-plus formulae, but rather involve an incentive mechanism similar to price-cap regulation.

The governance process is summarised in Table 4.1.

\subsubsection{Evaluation}

In evaluating the Energy Policy Council governance model the following points can be made:

- An advantage of the proposed model is that it separates political (EPC) and technocratic (regulator and management) decision-making, and attempts to find an appropriate differential between the two functions.

- This model also presents the opportunity to successfully implement a stakeholder governance model. The establishment of a single national Energy Policy Council provides all stakeholders, even representatives from rural constituencies, with the opportunity of influencing policy-making processes.

- The inclusion of stakeholders in the EPC, the use of a contract planning mechanism and the establishment of an electricity regulator with clearly defined powers to intervene in the governance process, will effectively place the industry at arm's-length from government. Although government will still be responsible for the general policy orientation of the industry, it will be protected to a degree from populist demands for delivery beyond reasonable bounds, by the mediating influence of stakeholders and the regulator.

- The Energy Policy Council ensures that electricity planning is integrated with national energy policy. Electricity supply to households, for instance, can be coordinated with other supply options. A similar coordination in the supply of 


\begin{tabular}{|c|c|c|c|c|}
\hline Role player & Represents & Appointed by & Functions & When \\
\hline $\begin{array}{l}\text { Minister of } \\
\text { Mineral and } \\
\text { Energy Affairs }\end{array}$ & $\begin{array}{l}\text { National } \\
\text { government }\end{array}$ & $\begin{array}{l}\text { Democratic } \\
\text { government }\end{array}$ & $\begin{array}{l}\text { Politically responsible for electricity supply } \\
\text { Appoints EPC } \\
\text { Determines electricity policy }\end{array}$ & $\begin{array}{l}\text { When required } \\
\text { When required }\end{array}$ \\
\hline $\begin{array}{l}\text { Energy Policy } \\
\text { Council }\end{array}$ & $\begin{array}{l}\text { Stakeholders } \\
\text { and national } \\
\text { and regional } \\
\text { government }\end{array}$ & $\begin{array}{l}\text { Minister, as } \\
\text { specified by } \\
\text { Act }\end{array}$ & Advises Minister on energy and electricity policy & Continuously \\
\hline $\begin{array}{l}\text { EPC Electricity } \\
\text { Committee }\end{array}$ & EPC & EPC & $\begin{array}{l}\text { Negotiates contract plan } \\
\text { Appoints chief executive }\end{array}$ & $\begin{array}{l}\text { Annually } \\
\text { When required }\end{array}$ \\
\hline $\begin{array}{l}\text { Board of } \\
\text { directors }\end{array}$ & Utility & $\begin{array}{l}\text { Chief } \\
\text { executive }\end{array}$ & $\begin{array}{l}\text { Develops 5yr business plan } \\
\text { Proposes performance indicators and target values } \\
\text { Negotiates contract plan } \\
\text { Reports on performance } \\
\text { Manages utility }\end{array}$ & $\begin{array}{l}\text { Annually } \\
\text { Annually } \\
\text { Annually } \\
\text { Annually }\end{array}$ \\
\hline Regulator & Public interest & Parliament & $\begin{array}{l}\text { Translates government policy into contract plan } \\
\text { framework } \\
\text { Reviews and audits: } \\
\text { - Govternment and utility contract plan proposals } \\
\text { - Investment plans } \\
\text { - Contract plan review submissions } \\
\text { Ombudsman } \\
\text { Regulates financial transfers } \\
\text { Partakes in EPC policy process where required }\end{array}$ & $\begin{array}{l}\text { When required } \\
\text { When required } \\
\text { When required }\end{array}$ \\
\hline
\end{tabular}

TABLE 4.1 The ESI governance process

energy to the industrial, commercial and other sectors will result in optimal energy utilisation.

- The transition of the ESI (discussed in the following chapter) is a process that will take several years to complete. This governance model has the advantage that, during the transition period, it can cope with both a single national distributor, and a few regional distributors.

The involvement of a broad range of stakeholders (including representatives of provincial government) in the EPC means that a deadlock in decision-making can occur and result in similar problems to those pointed out in the discussion of the Regional Electricity Council model. The possibility of a deadlock and poor decision-making will depend to a large degree on the balance of power in the EPC. It is suggested that national government should maintain a strong enough presence in the EPC to avoid deadlock situations.

- A disadvantage of the model is that, it is possible that government and politically appointed utility directors could conspire to exclude the regulator in the governance process, particularly if the EPC becomes totally dominated by government (which would fundamentally undermine its purpose). The desired arm's-length relationship between the utility and government will thus be undermined.

- This model, with its relatively sophisticated separation of powers and functions, will require careful explanation to political decision-makers, and accurate description in law. If the balance of powers is not maintained in the enacting laws, it will be successful. 


\section{Managing the transition}

A clear policy for restructuring the ESI, as outlined in the previous chapter, provides an end goal, but does not in any way help to deal with the practical complexities of managing the transformation of the current industry. This final chapter analyses questions concerning the management of the transition of the ESI, based on the assumption that agreement on an appropriate model for the ESI (or at least its desired characteristics), structured along the lines proposed in Chapter Four, can be reached.

\subsection{Objectives of transition}

The transition of the ESI will not only have to overcome obstacles to restructuring the industry; it will also have to simultaneously realise the objective of accelerated electrification in the context of a changing industry. Obstacles to short-term electrification will have to be overcome before the restructuring of the ESI can be completed. There are thus essentially two objectives for the transition of the ESI from the current status quo to the desired future dispensation:

- restructuring in terms of the agreed guidelines; and

- the simultaneous acceleration of electrification.

The key conditions for a successful transition of the ESI are outlined below. Thereafter, the experience of the National Electrification Forum (NELF) is reviewed, and different strategies for managing transition are discussed.

\subsection{Key conditions for the transition}

Most of the obstacles to transition exist as a result of the specific political, economic, social, and institutional conditions in South Africa. These obstacles point to factors crucial for success, the neglect of which will seriously affect the progress in the transition period. This section discusses the key issues concerning the transition, with the aim of highlighting the main problems that will have to be solved during this process.

\section{The powers and functions of sub-national government}

If regional or local government is given exclusive power over electricity in an interim or final constitution, the guidelines proposed above will be impossible to implement. It is vital to ensure that the powers and functions given to regional government do not preclude the possibility of implementing national governance functions. As indicated in previous chapters, the newly adopted South African constitution provides local, regional and national government with concurrent powers over the supply of electricity. The constitution could still be amended during the months leading up to the April 1994 election, and in the years thereafter, when the final South African constitution will be negotiated.

\section{The transfer of local government assets and liabilities}

Answers have to be found to the problems of transferring the electricity assets from municipalities, as well as dealing with existing electricity debts which have, in many cases, not been serviced for years. In every case, the details of take-over will have to be negotiated. Nationally agreed principles guiding the take-overs will facilitate the transition process. 
Section 14 of the Electricity Act (No 41 of 1987) states that, in the case of the take-over of electricity undertakings, the former undertaker has to be compensated for the "fair" value of the assets. It would clearly be impossible to compensate all municipalities for the take-over of their assets on the basis of, for example, replacement costs. With the corporatisation of electricity supply, themunicipal distributor assets would be transferred from one public undertaking to another. A strong case can thus be made out for the repealing of this provision of the electricity act. At the same time, it would be unrealistic to leave municipalities with debt associated with income-generating assets that have been expropriated from them. In principle, assets should thus be transferred to public utilities without compensation, but all existing liabilities associated with electricity assets, would have to be transferred with the assets.

\section{The financial impact on local government}

The electricity surpluses that are generated by the larger white cities as a result of their sales to commercial and industrial consumers have been an important source of revenue for many white municipalities for years. The National Electrification Forum supply-side database indicates that the transfer of electricity surpluses to general rates accounts in municipalities amounts to about R1,3 billion per year. These surpluses have not yet been compared to the operating losses realised by the electricity departments of many poorer local governments. Negotiators involved in local government restructuring are proceeding on the basis of optimistic assumptions about the availability and magnitude of these surpluses.

The proposal to establish distributors as "arm's-length" public corporations implies that they will be distinct financial entities that are independent from local government. The current municipal "structural" financial transfers will thus not be sustainable in the proposed future dispensation. This does not preclude the possibility of taxing electricity in a transparent manner in order to raise public funds, but it does mean that the current dependence of white ratepayers on the electricity surpluses raised from sales to industrial and commencial consumers will have to be terminated. Future unified local governments will be in dire need of revenue, and if electricity surpluses are no longer available, alternative revenue sources will have to be found.

\section{Financial viability in the confext of rapid electrification}

The financial viability of the industry has to be maintained during the transition process in order to ensure that the industry will be on a stable footing, capable of providing electricity in the future under conditions of increased economic growth and growing demand. Electrification programmes expose utilities to significant financial risk at the best of times. When a large electrification program is implemented by a fragmented industry and based on hastily drafted policies, is becomes increasingly difficult to determine and manage the increased financial risk.

The large capital and operating expenditure associated with electrification means that utilities are exposed to financial risk in the following ways:

\section{- Tariff risk}

During the highly politicised transition period, utilities face the risk that they could be expected to charge tariffs that do not enable them to meet their revenue requirement.

\section{- Consumption risk}

If electricity consumption is lower than expected, revenues will be lower than planned. The cumulative net funding requirement will thus be higher, and the financial position of the utility will be weaker. 
Utilities arealways exposed to a revenue recovery (non-payment) risk, but when facing large loan servicing requirements, the utility will be more vulnerable when revenues are not recovered. The advent of pre-payment meters has increased distributor capital expenditure, but will minimise the revenue recovery risk in the future.

- Technological risk

Technology choices for electrification can affect the financial viability of distributors for long periods into future. When distributors standardise on unproven technology, they run the risk of widespread future failure, which will necessitate either replacement or expensive maintenance programmes.

During the transitional period, electrification will be accelerated to meet a highly politicised popular demand for social services. Realistic governance (including tariff setting) and careful management will be required to minimise financial risk and ensure long-term financial sustainability.

\section{Tariffs that are affordable and legitimate}

In addition to the need for realistic tariff levels, other tariff-related problems, such as the unaffordability of electricity, controversy concerning the present patchwork of tariffs, and continued payment boycotts, pose significant obstacles to electrification. It will be crucial to establish tariffs that are affordable and legitimate, if the transition of the ESI and interim electrification is to take place successfully.

\section{Finance for electrification}

During the transition, access to finance for electrification has to be ensured (especially for non-Eskom distributors). The NELF could establish the proposed National Electrification Fund by lobbying government for a grant of about R0,5 to R1 billion by the next budget cycle. It could use a small proportion of the income generated from this grant to employ a handful of highly skilled professionals to manage the fund. The administration of the fund could be contracted out to Eskom or the Development Bank of Southern Africa, as proposed above.

- Negotiations could be entered into with other funders of electrification, such as the Development Bank of Southern Africa, the Independent Development Trust, the relevant government departments and Eskom (as a funder), to facilitate the pooling of low-cost finance so that the maximum the benefit can be derived from it. The fund could also issue bonds with government backing. Eskom's recently issued Electrification Participation Note is an example of the type of innovative initiatives that could be pursued to obtain finance.

In the long-term, the fund could bebrought directly under the control of the DMEA.

\section{Access and obligation to supply}

The present system that gives the first "right to supply" to local authority distributors in terms of the Electricity Act, prohibits capable distributors access to areas that are presently under-serviced and poorly managed. It also exempts distributors which have the resources necessary to electrify under-serviced areas from the obligation to supply them. This problem will have to be overcome in the short-term if electrification is to be accelerated during the transition of the ESI.

\section{Management capacity}

Managing the transition of the ESI will require the services of professionally skilled and experienced managers with an intimate knowledge of the industry. The services of such people must be retained by giving them security of employment and appropriate incentives.

\section{Human resources}


tions of service, pension funds, medical aid, management practices and career prospects must be carefully considered. The transfer of personnel and changes in employment conditions will have to be negotiated with the relevant trade unions.

\section{Development planning and coordination}

At present, electrification is undertaken without sufficient coordination with other training, employment, micro-enterprise and service-development programmes. The success and benefits of electrification will be significantly enhanced by coordinating development planning. A precedent can be set for the role of future Local Planning Committees by ensuring distributor participation in regional economic development forums and other regional development forums during the transition.

\subsection{Progress with ESI restructuring}

Since its establishment in May 1993, the National Electrification Forum has made considerable progress (at the time of writing, February 1994) in developing policies for a national electrification programme, and the development of a national electricity utility database to be used in planning the restructuring of the industry. The NELF has also reached agreement on the need to establish a national electricity regulator and a national electrification fund, but has not yet produced either a proposal for restructuring the ESI or a policy framework for tariff setting. It has therefore so far failed to address the most urgent issues.

The reasons for this failure are related to the nature of the NELF. The NELF is a consensus forum that consists of a wide range of stakeholders, including government, the African National Congress (ANC), major unions, large civic federations, consumer groups, representatives from white local government (the United Municipal Executive (UME), the Association of Municipal Electricity Undertakings (AMEU)) and Eskom. It is supposed to make decisions on a consensus basis, and no deadlock-breaking mechanism exists. The NELF is typical of a wide range of forums that sprung up in South Africa during the early nineties as precursors to the first democratic elections in April 1994. These forums have arisen from the need to establish legitimate decision-making bodies at a time when the Nationalist government has found it increasingly difficult to govern after acknowledging its illegitimacy, and agreeing to hold free elections. However, the NELF process is itself flawed for the following reasons:

a) The representation of the AMEU and Eskom is problematic. The AMEU supposedly represents the municipal electricity undertakings, but in reality they act in the interests of white local government, by whom they are appointed and to whom they have to report. The AMEU, and to a lessor extent, the Eskom delegations, are also acting in the interests of senior management, rather than the industry as a whole. If it was explicitly stated that they were representing an employee group, the negotiation process would be able to proceed more easily.

b) There is confusion about the nature of the conflict that has to be resolved by the NELF. For some, it is a conceptual debate about the most effective way of organising and governing the electricity sector in South Africa, and about the role that the state should play therein in essence, a debate about industry effectiveness and efficiency. For others, the ESI is seen as a vehicle for transferring resources and redressing social inequalities essentially, a debate about the promotion of social equity. Then there is also a group who see the NELF as a site of negotiation where they have to ensure their self-preservation. Hopefully, this confusion will be partly alleviated by the time demands are put frankly on the table in the final effort to reach an agreement. 
c) Being a consensus decision-making body, NELF participants need to compromise in order to reach decisions. If a participant has no incentive to compromise in order to reach a decision, or has an incentive to stall decisions, a consensusbased process will fail. It seems clear that AMEU, together with the local government representatives, the UME, have a stake in the status quo and will not support the consensus process. Unless a deadlock-breaking mechanism is agreed to, the NELF will fail to make final proposals on major issues facing the ESI.

d) One of the reasons for the establishment of the NELF was that there existed no party with legitimate power to make decisions on ESI restructuring. However, the NELF itself continues to suffer from this problem. Participants need to have a sense of the power base of others in order to know what importance to attach to their positions. Although participants do not represent constituencies of the same size, they have an equal say on the Forum. As a result, objections from even the smallest constituency can stall the process.

e) The question of whether electricity supply should be removed from local government remains the single biggest point of contention in the NELF. Although the AMEU and the UME are represented on the NELF, they do not effectively represent the constituency that would be most affected by this issue. Another forum, the Local Government Negotiating Forum (LGNF), has been the site for negotiations concerning local government reform in South Africa. The NELF has thus excluded an important group of stakeholders, while attempting to negotiate an issue related to the restructuring of local government. The AMEU and UME representatives that are involved in the NELF, are not directly involved in the LGNF, and are thus not able to contribute to the process other than by stalling it. Further progress in the NELF will depend on the degree to which it manages to engage the central stakeholders in local government restructuring. The NELF will have to develop a thorough understanding of the concerns and interest of the local government lobby in order to facilitate a negotiated agreement.

f) A final problem with the modus operandi of the NELF, is that it confuses the political and technocratic decision-making processes that need to take place in order to restructure the ESI. It seems highly impractical to expect stakeholder politicians to cooperate with relatively neutral technical experts in wading through the quagmire of complicated considerations involved in developing a model for ESI restructuring. A coherent model for the ESI cannot be developed solely on the basis of political horse-trading, but needs to be informed by technical expertise.

To enable an acceptable model for the ESI to be determined, political and technocratic processes need to be separated and then linked in a way that is transparent. A future democratic government should consult with other stakeholders to establish a mission statement for the ESI over the next ten years. A technical task group should then be appointed to develop and evaluate two or three alternative models on the basis of the mission statement, and to present them to government for a final decision. 


\subsection{Strategies for the transition}

Different strategies can be followed to facilitate the transition of the ESI towards an end goal. These strategies will have to address the key issues for transition, as well as the current problems experienced by the NELF, as discussed above. In practice, the transition will be a process of change that involves so many stakeholders at different levels that it will be very difficult to control its final outcome. Experience with changemanagement will be required to limit the potentially large 'transaction costs' that the restructuring could incur. Political processes at different levels will be required to obtain a final decision to make the change, and to maintain the momentum to reach the desired objective. Care needs to be taken to motivate both managers and the work force, and to provide them with incentives to ensure the success of the restructuring.

Two possible strategies are discussed below.

\section{Municipal distributors and Eskom}

One option will be to follow the route of the present local government negotiations, which will lead to the formation of rationalised municipalities and metropolitan governments. This will bring about the amalgamation of bulk service provision, including electricity. The remaining common (RSA) and homeland rural areas and villages could be supplied by Eskom, as is currently the case in the common areas of South Africa. Municipalities will presumably remain responsible for the supervision of performance and the setting of tariffs.

The obvious advantage of this route is that it will happen by default. The main disadvantage will be that all control will still be situated at a local level, thereby entrenching electricity supply in the hands of the new local government. It would thus create difficulties in completing the transition process, and in accelerating and sustaining a national electrification programme.

\section{A single distributor}

Another possibility is that a single body could be mandated to coordinate distributors as an interim step, before the future distribution dispensation is established.

Restructuring will be a slow process, necessitating careful management. It will be important to establish effective control, management and information mechanisms during the transition period. The most urgent need is thus not to structurally combine distributors along the future borders, but rather to establish control structures that will facilitate the coordination of restructuring and electrification. If the activities of distributors can be coordinated on a national and regional basis, many of the obstacles to restructuring and interim electrification would be overcome.

During the transition, it will be necessary to have policy formulated on a national level. Management of the transition process will also have to be coordinated nationally. The National Electrification Forum (or a body with similar broad legitimacy) will be able to determine policy, but will not be able to coordinate the management of the transition. It will thus be necessary to establish a distributor management body on a national level. This body could employ some of the most senior managers in the industry to manage the transition in terms of the policy agreed to by the NELF. During the transition, the beginnings of the new governance system can be created by establishing the first contract plan between the NELF and distribution management, and by creating a national regulator with powers over the whole industry.

In practice, a combination of the two strategies can be managed by allowing the default municipal restructuring to go ahead, while the major political decisions are made. A small amendment to the Electricity Act could be made to establish the 
national regulator and require all electricity undertakings to operate under a licence issued by the regulator. Once these steps have been completed, the transition can proceed on the basis of close cooperation between the policy making body the NELF the national regulator, and the national distribution management.

\subsection{Concluding summary}

The proposed transition of the ESI will for the first time fundamentally change the way in which electricity is distributed in South Africa. It will enable the industry to address the challenge of providing all South Africans with electricity, while protecting its financial viability in order to maintain a low-cost electricity supply to support a growing economy. This paper has focused on the institutional issues that will be important for the establishment of a new ESI model. Questions concerning the structure, and especially, the governance of the ESI, arecritical to the success of a restructured industry. By drawing on international experience, this paper develops a framework for the governance of a publicly owned ESI in South Africa.

The particular contribution to knowledge of this paper lies in its application of international experience to the South African situation, and specifically in its distinction between the role of politics and expertise in the governance of the ESI. On the basis of this distinction, it develops governance models that are based on a contract-plan mechanism, but relies on the role of stakeholders and an independent regulator. In this way, it attempts to find an appropriate balance between the equity concerns of a new democratic government, and the efficiency needs of a developing economy. 


\section{References}

AMEU (Association of Municipal Electricity Undertakings), 1993. Presentation on proposals for possible regional boundaries for future electricity undertakings. Unpublished report presented to the National Electrification Forum Management Committee 'Bosberaad' on 12 August 1993.

Besant-Jones, J E 1992. Reforming the policies for electric power in developing countries. Unpublished draft paper. World Bank, Industry and Energy Department.

Clare, D J 1989. Privatisation of Eskom: the mining industry's view. Electron, November/December 1989: 15.

Cordukes, P A 1990. A review of regulation of the power sectors in developing countries. Washington: World Bank.

CRIC(Community Resource Information Centre) 1989. Privatisation: selling off the public sector. South African labour bulletin, 14 (4): 100-107.

De Oliviera, A 1991. The key issues facing the electricity systems of developing countries: Synthesis report of the Cooperative Programme on Energy and Development. Luxembourg: Commission of the European Communities.

De Oliviera, A. 1992 Electricity system performance and opportunities for developing countries: Synthesis report of the Cooperative Programme on Energy and Development. Luxembourg: Commission of the European Communities.

De Oliviera, A \& MacKerron, G 1992. Is the World Bank approach to structural reform supported by experience of electricity privatization in the UK? Energy policy, 20 (2): 153-62.

De Villiers, W J 1984. Report of the Commission of Enquiry into the Supply of Electricity in South Africa: Pretoria: Government Printer.

Department of Mineral and Energy Affairs (DMEA) 1992. The development of the electricity distribution industry in South Africa: Final report to the Minister of Mineral and Energy Affairs. Pretoria: Government Printer

Dingley, C 1993. (Department of Electrical Engineering, University of Cape Town.) Personal communication.

Eskom, 1993a. 1992 Eskom annual report. Sandton: Eskom.

Eskom, 1993b. Eskom statistical yearbook: 1992. Sandton: Eskom.

Fells, I \& Lucas, N 1992. UK energy policy post-privatisation. Energy policy, 20 (5): 386-9.

Foley, G 1992. Rural electrification: the institutional dimension. Utilities policy, 2: 283-9.

Hasson, G D 1992. The reforming of the Argentine electricity system. Unpublished paper prepared for IDEE/FB, Bariloche.

Hasson, G D, Hasson, R A, Dubrovsky, H \& Groisman, F 1992. Institutional structure, regulation and performance of the electricity sector in Argentina. COPED discussion paper no. 11, Science Policy Research Unit, University of Sussex.

Horwitz, R B 1989. The irony of regulatory reform: The deregulation of American telecommunications. New York: Oxford University Press.

Horwitz, R B 1992. Regulating parastatals. Paper presented to the Economic Trends Group meeting, University of Cape Town, June 1992.

Horwitz, R B 1993. The development of the institutional and regulatory structure of the South African electricity supply industry. Unpublished paper. Department of Communication, University of Califormia, San Diego.

MacKerron, G 1993. (Science Policy Research Unit, University of Sussex.) Personal communication. 
MacKerron, G 1994. (Science Policy Research Unit, University of Sussex.) Personal communication.

McGowan, F 1991. COPED paper for 1991/92. Unpublished paper. Science Policy Research Unit. University of Sussex.

McGowan, F \& Thomas, S D 1992. Electricity in Europe: Inside the utilities. London: FT Business Information.

Merz \& McLellan. 1920. Electric power supply in the Union of South Africa. London: Unpublished consultant report presented to Prime Minister Jan Smuts in April 1920.

Morgan, K J 1993a. Determinants of price regulation in electricity utilities. Unpublished MBA thesis, University of the Witwatersrand.

Morgan, KJ 1993b. Personal communication.

Munasinghe, M \& Sanghvi, A 1989. Recent developments in the US power sector and their relevance for the developing countries. Washington: World Bank.

NEES 1993. The National Electrification Economic Study: phase 1, draft report by the Module II: Public Sector Economic Impact Study Team on financing requirements of national electrification scenarios, December 1993. Unpublished draft report for the National Electrification Forum, Johannesburg.

NELF 1993. National Electrification Forum Supply Side Data Base. Johannesburg: National Electrification Forum.

Penn, D W 1992. The electricity industry in the 1990 s public service or commercial operator. Unpublished paper. World Electricity Conference, London.

PFSK [Permanent Finance Liaison Committee]. 1991. Tussentydse verslag van die PFSK-werkgroep insake 'n streeksbenadering tot elektrisiteitsverspreiding. Unpublished report for the Department of Finance, Pretoria.

Rodriguez, F 1987. UK government controls and the electricity supply industry since 1980. Energy policy, 15 (5): 463-73.

Steyn, G \& Theron, P 1992. Policy proposals on electricity and local government in South Africa. Unpublished paper prepared for Planact, Johannesburg.

Surrey, J 1986. Government and the nationalised energy industries. Energy UK 1986: 41-7.

Tenenbaum, B, Lock, L \& Barker, J 1992. Electricity privatization: structural, competitive and regulatory options. Energy policy, 20 (12): 1134-60.

Teplitz-Sembitzky, W 1990. Regulation, deregulation, or reregulation - what is needed in the LDCs power sector? Washington: World Bank.

Theron, P (Ed) 1992. Proceedings of the ANC National Meeting on Electrification, 6-7 February 1992, University of Cape Town. Bellville: CDS

Van Horen, C 1994. Financing and economic implications of household energy policies. Cape Town: Energy for Development Research Centre.

Venter, P R 1992. (Secretary, Permanent Finance Liaison Committee, Department of Finance.) Personal communication.

Wirtshafter, R M \& Shih, E 1990. Decentralization of China's electricity sector: Is small beautiful? World Development 18 (4): 505-12.

World Bank 1993a. The World Bank's role in the electric power sector: Policies for effective institutional, regulatory and financial reform. Washington: World Bank.

World Bank 1993b. Power supply in developing countries: will reform work? proceedings of a Roundtable co-sponsored by the World Bank and Electricité de France, Washington, April 27-28, 1993. Washington: World Bank.

Yarrow, G 1989. Does ownership matter. Privatisation \& competition: A market prospectus. London: Institute of Economic Affairs.

Yates, P 1988. Improving power system efficiency in the developing countries through performance contracting. Washington: World Bank. 


\title{
PROJECT DESCRIPTION
}

A major two year research project was launched by the Energy for Development Research Centre in April 1992. It aims to investigate policy options for widening access to basic energy services for the urban and rural poor in South Africa. Research papers are being produced in the following areas:

\section{Background papers}

Research outline

Integrated energy planning: a methodology for policy analysis and research

Development context for energy planning in South Africa

Background on South African energy system

\section{Energy demand analysis}

Energy demand in underdeveloped urban and rural areas

Rural areas

Energy for rural development: an introduction and overview

Energy and small-scale agriculture

Rural household energy supply options

Afforestation and woodland management

Remote area power generation options

\section{Urban areas}

Household energy supply in formal and informal urban settlements Energy and informal sector production

\section{Ancillary sector}

Energy and mass transportation*

Key supply sector

Electricity distribution sector*

Cross-sectorial studies

Energy efficiency and conservation*

Energy and environment*

Southern Africa linkages*

Investment requirements and financing mechanisms*

Pricing policy*

Institutional analysis*

\section{Policy options}

A concludir. document will draw together key policy conclusions

* The scope of these studies is restricted to energy issues concerning the urban and rural poor.

\section{EDRC}

The Energy for Development Research Centre is located at the University of Cape Town. Its objectives are to study energy related problems of developing areas in Southern Africa, and possible ways to address them.

EDRC seeks to achieve its objectives by:

- undertaking research projects;

- running a specialist postgraduate programme to support research projects and to train personnel to contribute to this field;

- transferring relevant information to user groups by offering consulting services and running workshops, and through publishing books, journal papers, reports, leaflets and design and user manuals.

\author{
Energy for Development Research Centre \\ Energy Research Institute \\ University of Cape Town \\ Private Bag \\ Rondebosch 7700 \\ South Africa
}




\section{PAPERNO14a}

\section{Restructuring the South African electricity supply industry}

Grové Steyn

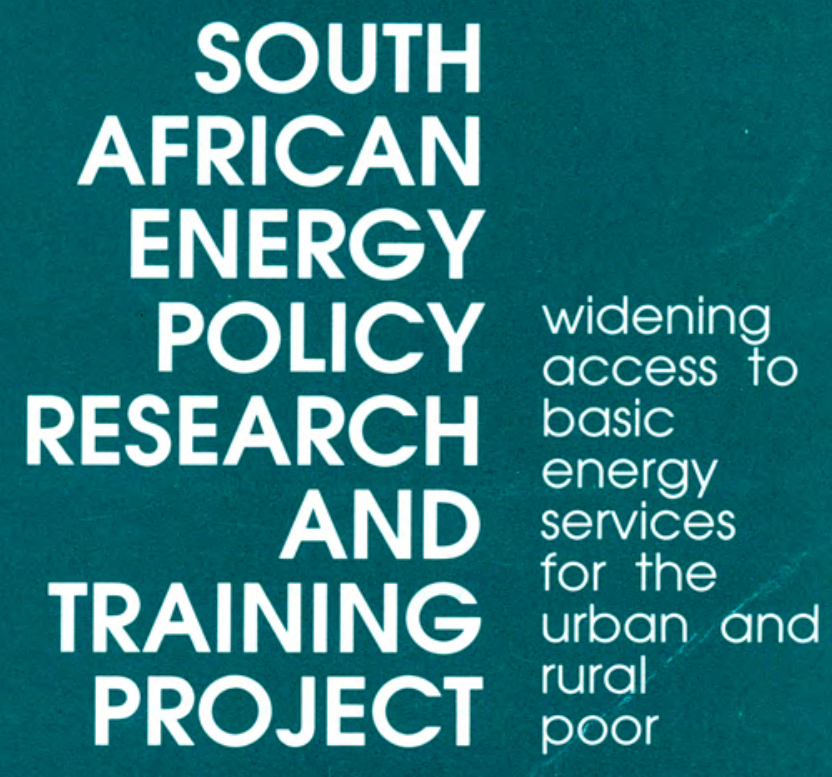

